\title{
Application of BET_EF to Mount Etna: a retrospective analysis (years 2001-2005)
}

\author{
Alfonso Brancato ${ }^{1, \star}$, Stefano Gresta ${ }^{1}$, Salvatore Alparone ${ }^{2}$, Daniele Andronico ${ }^{2}$, Alessandro Bonforte ${ }^{2}$, \\ Tommaso Caltabiano ${ }^{2}$, Ornella Cocina ${ }^{2}$, Rosa Anna Corsaro ${ }^{2}$, Renato Cristofolini ${ }^{1}$, Giuseppe Di Grazia ${ }^{2}$, \\ Giovanni Distefano $^{1}$, Carmelo Ferlito ${ }^{1}$, Salvatore Gambino ${ }^{2}$, Salvatore Giammanco ${ }^{2}$, Filippo Greco ${ }^{2}$, \\ Rosalba Napoli ${ }^{2}$, Laura Sandri ${ }^{3}$, Jacopo Selva ${ }^{3}$, Giuseppina Tusa ${ }^{1,2}$, Marco Viccaro ${ }^{1}$
}

\author{
${ }^{1}$ Università di Catania, Dipartimento di Scienze Geologiche, Catania, Italy \\ ${ }^{2}$ Istituto Nazionale di Geofisica e Vulcanologia, Sezione di Catania, Osservatorio Etneo, Catania, Italy \\ ${ }^{3}$ Istituto Nazionale di Geofisica e Vulcanologia, Sezione di Bologna, Bologna, Italy
}

\author{
Article history \\ Received November 22, 2010; accepted June 15, 2011. \\ Subject classification: \\ Experimental volcanism, Volcano monitoring, Volcanic risk, Statistical analysis, Collections.
}

\section{ABSTRACT}

Advances in volcano monitoring and forecasting need a multidisciplinary collaborative framework. In light of this, a Bayesian Event Tree (BET) approach was performed by the application of the BET for Eruption Forecasting (BET_EF) code to analyze the space-time distribution of the volcanic activity of Mount Etna from 2001-2005. First, a reliable monitoring dataset was set up after some sessions to elicit geophysical, volcanological and geochemical 'precursor' parameters. A constant unrest probability of $100 \%$, with a magma involvement usually greater than 95\%, was computed throughout the time period analyzed. Eruption probabilities higher than $90 \%$ were estimated a few days before the onsets of the 2001 and 2002-2003 flank eruptions. Values slightly higher than $75 \%$ were observed during the lava fountaining period in June-July 2001. However, the probabilities flattened to around 30\% for the 2004-2005 flank eruption. With suitable data, a good depiction of the actual location of the eruptive scenario for the 2001 and 2002-2003 events was provided. Conversely, the size of the eruptions was not indicated.

\section{Introduction}

One of the major goals of modern volcanology is to set up sound risk-based decision making for land-use planning and emergency management. This topic has maximum priority especially for volcanoes located close to densely urbanized areas, such as Mount Etna.

This necessarily requires improvements to the present surveillance of volcanic systems, to allow near real-time accurate responses through the use of innovative and boundary techniques. Volcanic hazard must be managed with reliable estimates of quantitative long-term and shortterm eruption forecasting; however, the large number of observables that are involved in any volcanic process suggests that a probabilistic approach is probably the most suitable tool in forecasting.

Two styles of eruptive activity typically occur for Mount Etna [i.e. Cristofolini et al. 1988]. Persistent gas emissions and frequent strombolian eruptions, which are sometimes accompanied by minor lava flows, take place from one or more of the four prominent summit craters: the Central Crater, Bocca Nuova, the North-East Crater, and the SouthEast Crater. Instead, flank eruptions occur less frequently (at intervals of years), and they originate from fissures that usually open progressively downwards from near the summit; their durations can span from days to years.

The aim of the present study was for a retrospective analysis to quantify the probabilistic estimations of eruptions and relative vent locations for suitable lava-flow hazard assessment for Mount Etna volcano, through the application of the Bayesian Event Tree for Eruption Forecasting (BET_EF) code [Marzocchi et al. 2004, 2008]. Following the pioneering test run that was performed with the BET_EF code for the 2001 flank eruption of Mount Etna volcano [Brancato et al., in press], we wanted to estimate the probabilities along a selected path (Figure 1a) for the time period of January 2001 to April 2005.

The present application represents the first efforts at an open-conduit active volcano to merge all of the relevant monitoring information in a truly objective manner, and over a long time span of more than four years. The initial results suggested that the monitoring dataset adopted was suitable to address how a future eruption might progress for Mount Etna volcano. In addition, the 2001 flank eruption is considered as a changing point in some of the internal dynamics of the 


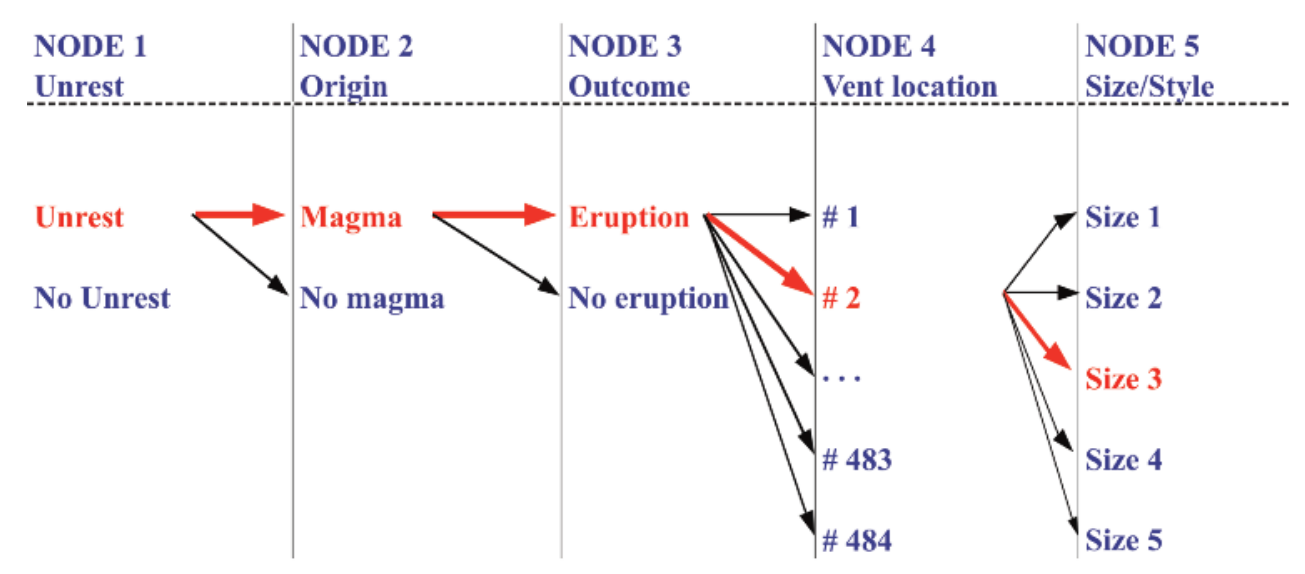

a.

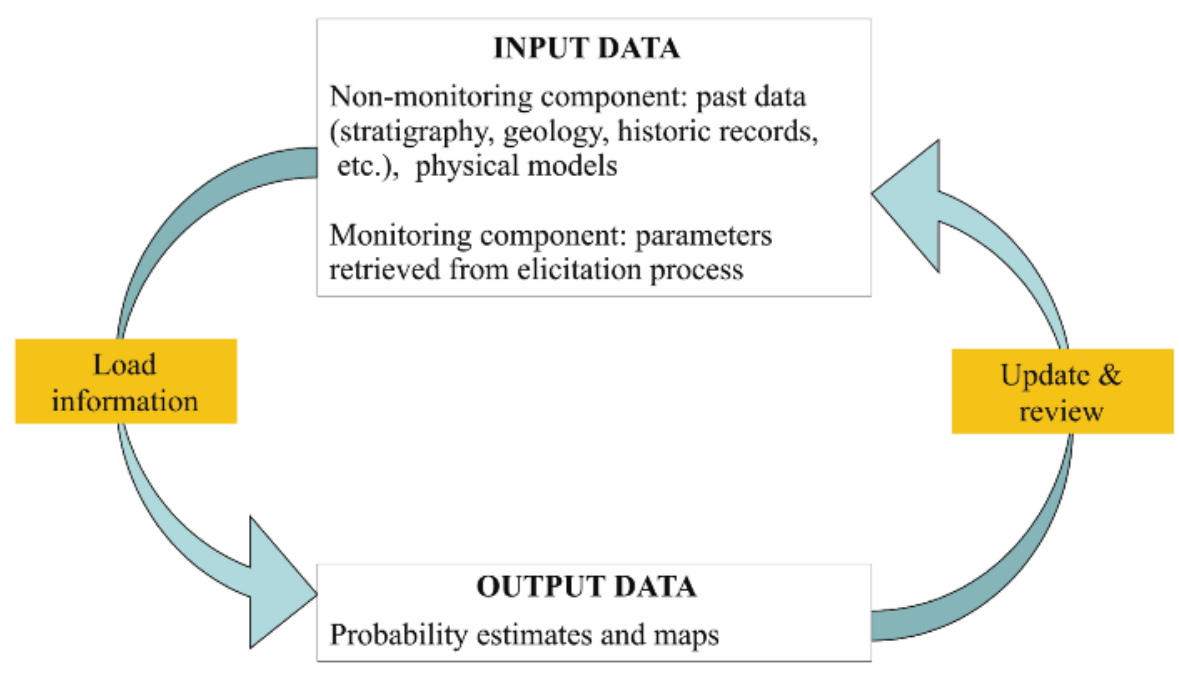

b.

Figure 1. a) General scheme of the BET_EF code (selection of the path, within the event tree), as adapted for the present application. b) Simplified flowchart of the run process.

volcano, and the parameters values gave some new insights into the post-2001 condition. Therefore, the pre-existing 2001 dataset (January 1-July 23 2001) [Brancato et al., in press], is reviewed, and is merged with the post-2001 values. First, this leads to a review of the probabilities estimated for the 2001 eruption. Then the BET_EF code is applied for 2002-2005, during which period there were two further Mount Etna flank eruptions, from October 2002 to January 2003, and from September 2004 to March 2005. Finally, the inter-eruptive time period is also analyzed.

\section{The Bayesian Event Tree for Eruption Forecasting code (version 2.1)}

The BET_EF model is based on the event tree philosophy as assessed by Newhall and Hoblitt [2002]. The concepts of vent location, epistemic and aleatory uncertainties, and a fuzzy approach for monitoring measurements, that is needed to simulate the expert opinion with a given degree of anomaly of the parameters observed, are considered in the present version of the code. All of the technical details are described in Marzocchi et al. [2008], and we refer the reader to that study for all of the settings of the code.

Nevertheless, some brief explanation is due. A BET is a graphic representation of a specialized branching of events in which the individual branches are alternative steps from a general prior event, and where they evolve into increasingly specific subsequent states. Then, this BET attempts to graphically display all of the relevant possible outcomes of volcanic unrest in progressively higher levels of detail. The procedure is set to estimate an a-priori probability distribution based upon theoretical knowledge, to accommodate this using past data, and to modify this further using current monitoring data.

The code is divided into five nodes. The first three nodes, 1, 2 and 3, have two possible outcomes, and are mutually exclusive and exhaustive in the time interval $\left[\mathrm{t}_{0}, \mathrm{t}_{0}+\tau\right]$. The last two nodes, 4 and 5, are set by the user (Figure 1a). Here, $\mathrm{t}_{0}$ is the time at which the volcano is in an unrest condition, 
and $\tau$ represents the forecast time window set on the basis of the observed typical time scale of the variations of the state of the volcano under study. In our case, we fixed $\tau=1$ week, coherent with the number of weeks in which unrest has been experienced [Brancato et al., in press].

Generally speaking, node 1 refers to the probability of having unrest in the above time interval, node 2 refers to the probability of having magmatic unrest (other causes can be considered as well; e.g. hydrothermal or tectonic activity) under the condition where unrest is detected, and node 3 refers to the probability that magma will reach the surface after the magmatic unrest (i.e. the occurrence of an eruption). The following node 4 refers to the probability that the eruptive vent will be located at a specific site, and provided that an eruption is ongoing; the final node 5 refers to the probability of the size/style of an eruption that occurs at a specific vent location.

The code consists of nonmonitoring and monitoring components, which are computed by Bayesian inference. For the nonmonitoring component, the a-priori distribution at each node describes general knowledge about that specific node (e.g. expert opinion and/or similar volcanic activity worldwide). This is represented by a 'best-guess' probability, as well as a relative weight that is expressed as a number $\Lambda$ of equivalent data [Marzocchi et al. 2004, 2008].

The a-priori distribution of the monitoring component is derived using parameters that are usually managed and measured during volcano surveillance procedures. Then, this a-priori distribution is adapted according to a likelihood function if past data are available from actual monitored unrest or eruptive events.

When no unrest is observed, long-term forecasting is established, whereas, by using monitoring data, the code can be used calculate short-term estimates inside the forecast time window.

For long-term forecasting, an a-priori model that deals with the present tectonic and volcanic structure of Mount Etna is considered. The model is mainly based on the past vent locations of the flank eruptions for Mount Etna over the last 400 years [Project V3-Lava 2010]. Considering the variations in the information through time, and its relationship to the structural setting of the volcano, we can also define an aposteriori probability map for the next vent opening.

For short-term forecasting of vent opening hazard assessment, the monitoring has a leading role. This is primarily based on seismological data, which are integrated with ground deformation, geochemical, petrological, gravimetric and magnetic parameters. Specific monitoring parameters are set only for the first three nodes, and all of the parameters set for the preceding nodes can be suitable for assessment of the future vent-opening probability. Parameter values describe the 'state' of Mount Etna volcano, and they are more detailed through the subsequent nodes of the code.

\section{Mount Etna volcano monitoring and eliciting the monitoring parameters}

Mount Etna is one of the best monitored volcanoes worldwide. The aim of this monitoring is to define the state of its activity through detection and measurement of some of the parameters that are directly linked to deep magma movements. Although the origins of these precursor phenomena were known in the past, it was only starting from the early 1960s that the data were collected routinely, when different instrumental networks were deployed on the volcanic edifice.

Seismic precursors include both volcano-tectonic earthquakes and volcanic tremors, which are typical of openconduit volcanoes, and which arise mainly due to the gases inside the conduit. Increasing trends for both of these parameters are usually observed when a flank eruption takes place [Alparone et al. 2003, Patanè et al. 2003, Bonaccorso et al. 2004, Falsaperla et al. 2005].

Strain deformation arises when an uplifting of the volcanic edifice occurs. These uplifts usually increase until the magma reaches the surface [Bonaccorso et al. 2002, Bonforte et al. 2004, Aloisi et al. 2006].

Gravimetric and magnetic data can be linked to magma intrusive processes. As with the above parameters, gravimetric and magnetic data show increasing trends during an unrest phase, prior to an upcoming eruption [Carbone et al. 2003, Del Negro et al. 2004, Carbone and Greco 2007].

The geochemical fluids here considered are the emissions of $\mathrm{SO}_{2}$ and $\mathrm{CO}_{2}$ from the summit crater and the soil, respectively. Both of these parameters are usually observed to have a decreasing trend some months before the occurrence of a flank eruption [Bruno et al. 2001, Aiuppa et al. 2004].

Finally, petrological analysis allows the reconstruction of the eruptive dynamics through a study of the magma composition [Andronico et al. 2005, Corsaro et al. 2009].

These relative measurements, and the analysis and interpretation of these parameters, can provide an understanding of whether Mount Etna is evolving towards volcanic activity.

For the present BET_EF application to Mount Etna, we need to look at the monitoring component as the most informative part of the short-term forecasting. Therefore, the monitoring parameters have to be reliably set, as well as the relative thresholds, the inertia time window of the expected anomaly, and the weights.

An elicitation process based on discussions was used to provide the whole dataset used in the present study. The experiment here involved the researchers who usually manage the monitoring data for Mount Etna, through direct call-up. Several meetings took place among the authors of the present study, as experts in at least one of the above-cited disciplines, and a reliable dataset of monitoring parameters for nodes 1, 2 and 3 was set up. A feedback process produced improved work-flow between the qualitative and quantitative 


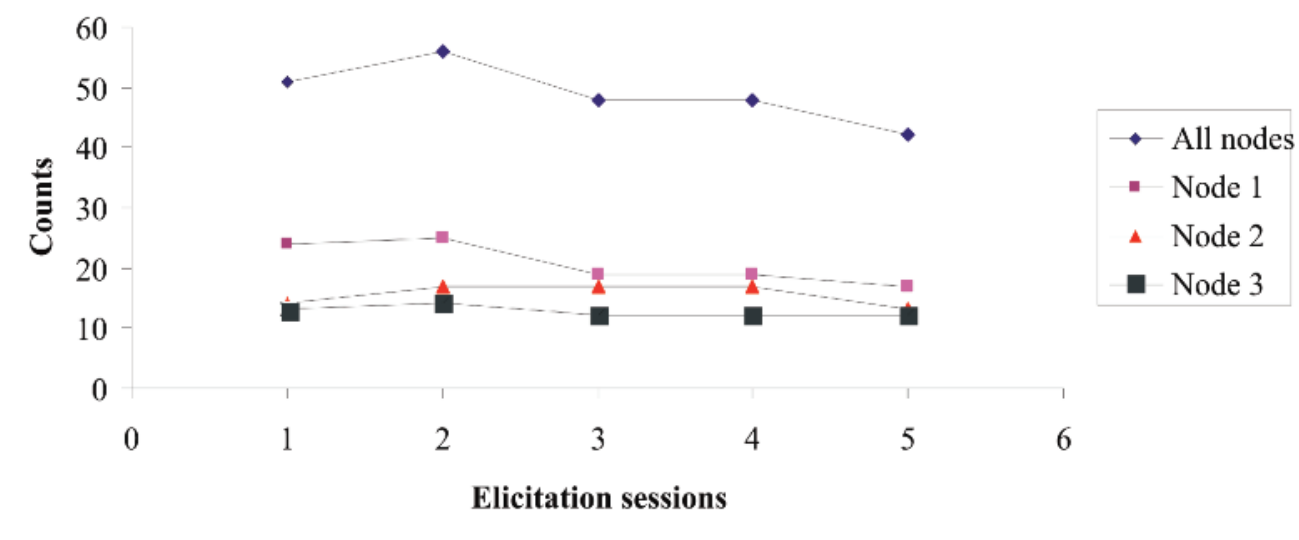

Figure 2. Numerical evolution of the monitoring dataset, as retrieved from the elicitation sessions.

Input Parameter

Data/Thresholds/Inertia

NODE 1: Unrest/No Unrest

\begin{tabular}{|c|c|}
\hline Prior distribution & No info (uniform distribution) \\
\hline Past data & $\mathrm{n}_{1}=1047$ weeks; $\mathrm{y}_{1}=36$ \\
\hline Number of earthquakes ( $\mathrm{D} \geq 200 \mathrm{~km} ; \mathrm{M}=5+$; Tyrrhenian slab) & $>1$ day $^{-1} ; 90$ days \\
\hline Number of VT earthquakes (M=3+; Pernicana Fault) & $>1,3$ day $^{-1} ; 60$ days \\
\hline Number of VT earthquakes ( $\mathrm{D} \geq 20 \mathrm{~km} ; \mathrm{M}=3+$; NW sector) & $>1,3$ month $^{-1} ; 150$ days \\
\hline Number of VT earthquakes $(\mathrm{M}=1+)$ & $>5-50$ day $^{-1} ; 180$ days \\
\hline Tremor amplitude duplication in $24 \mathrm{~h}$ & $=1 ; 30$ days \\
\hline W flank dilatation & $>0.011 ; 0.016 \mu$ strain $_{\text {day }}{ }^{-1} ; 365$ days \\
\hline Serra Pizzuta - M. Stempato line & $>0.027 ; 0.055 \mu$ strain day ${ }^{-1} ; 180$ days \\
\hline M. Silvestri - Bocche 1792 line & $>0.027 ; 0.082 \mu$ strain day ${ }^{-1} ; 180$ days \\
\hline EDM & $>0.068 ; 0.096 \mu_{\text {strain day }}{ }^{-1} ; 365$ days \\
\hline Deformation Pernicana Fault & $>0.008 ; 0.019 \mathrm{~cm} \mathrm{day}^{-1} ; 90$ days \\
\hline Clinometric variation $\left(>0.033 \mu \mathrm{rad}_{\text {day }}{ }^{-1}\right.$; CDV station $)$ & $=1 ; 365$ days \\
\hline $\mathrm{SO}_{2}$ emission $^{\star}$ & $<1000-1500$ ton day ${ }^{-1} ; 90$ days \\
\hline $\mathrm{CO}_{2}$ emission (P39 station) & $>2000-3000 \mathrm{~g} \mathrm{~m}^{-2}$ day $^{-1} ; 180$ days \\
\hline Gravity (E-W profile) & $>0.33 ; 0.50 \mu$ gal day $^{-1} ; 60$ days \\
\hline Gravity (N-S profile; seasonal) & $>0.50 ; 0.67 \mu$ gal day $^{-1} ; 60$ days \\
\hline Ash emission & $=1 ; 90$ days \\
\hline
\end{tabular}

NODE 2: Magma/No Magma

Prior distribution

0.95

$1^{\mathrm{b}}$

Past data

No data

Number of VT earthquakes $(\mathrm{M}=2+$; W sector)

Number of VT earthquakes $(\mathrm{D}<5 \mathrm{~km})$

Number of seismic swarms ( $>30$ earthquakes day $\left.{ }^{-1}\right)$

W flank dilatation

Serra Pizzuta - M. Stempato line

M. Silvestri - Bocche 1792 line

Clin. Variation of the mean (CDV, MNR, MSC stations)

$$
\mathrm{SO}_{2} \text { emission }
$$

$\mathrm{CO}_{2}$ emission (P78 station)

Gravity (E-W profile)

Gravity (N-S profile; seasonal)

$\begin{array}{cc}0.95 & 1^{\mathrm{b}} \\ \text { No data } & \\ >10,15 \text { day }^{-1} ; 90 \text { days } & 2^{\mathrm{a}} \\ >3-10 \text { day }^{-1} ; 90 \text { days } & 2^{\mathrm{a}} \\ =1 ; 60 \text { days } & 2^{\mathrm{a}} \\ >0.010,0.015 \mu \text { strain day }^{-1} ; 365 \text { days } & 1^{\mathrm{a}} \\ >0.055,0.548 \mu \text { strain day }^{-1} ; 180 \text { days } & 1^{\mathrm{a}} \\ >0.080,0.548 \mu \text { strain day }^{-1} ; 180 \text { days } & 1^{\mathrm{a}} \\ >0.6-1.2 ; 1 \text { day }^{\mathrm{a}} & 2^{\mathrm{a}} \\ >2000-5000 \text { ton day }^{-1} ; 30 \text { days } & 1^{\mathrm{a}} \\ >120-250 \mathrm{~g} \mathrm{~m}^{-2} \text { day }^{-1} ; 60 \text { days } & 1^{\mathrm{a}} \\ >0.50,1.00 \mu \text { gal day }^{-1} ; 30 \text { days } & 1^{\mathrm{a}} \\ >0.67,1.33 \mu \text { gal day }^{-1} ; 30 \text { days } & 1^{\mathrm{a}} \\ =1 ; 90 \text { days }^{2} & 1^{\mathrm{a}}\end{array}$


NODE 3: Eruption/No Eruption

Prior distribution
Past data
Number of VT earthquakes $(\mathrm{D}<5 \mathrm{~km})$
Number of VT events
Tremor (STA / LTA maximum peak $)$
W flank dilatation
Serra Pizzuta - M. Stempato line
M. Silvestri - Bocche 1792 line

Clin. Variation of the mean (CDV, MNR, MSC stations)

$$
\mathrm{SO}_{2} \text { emission }
$$

$\mathrm{CO}_{2}$ emission (P78 station)

Gravity (E-W profile)

Gravity (N-S profile; seasonal)
No info (uniform distribution)

$$
\begin{aligned}
& \mathrm{n}_{3}=36 ; \mathrm{y}_{3}=26 \\
> & 40-100 \text { day }^{-1} ; 1 \text { day } \\
> & 70-100 \text { day }^{-1} ; 1 \text { day } \\
> & 2,4 \text { day }^{-1} ; 1 \text { day }
\end{aligned}
$$

$>0.014,0.027 \mu_{\text {strain day }}{ }^{-1} ; 30$ days

$>0.548,1.918 \mu \mu_{\text {strain day }}{ }^{-1} ; 30$ days

$>0.548,1.918 \mu$ strain day $^{-1} ; 30$ days

$>1.2-2.5 ; 1$ day

$>8000-11000$ ton day ${ }^{-1} ; 7$ days

$<0-120 \mathrm{~g} \mathrm{~m}^{-2}$ day $^{-1} ; 7$ days

$>1.00,1.67 \mu_{\text {gal day }^{-1}} ; 15$ days

$>1.67,2.00 \mu$ gal day $^{-1}$; 15 days

NODE 4: Vent location
See text for details

See text for details

NODE 5: Eruption size (five sizes, according past data)

Prior distribution

$$
\begin{aligned}
& \text { size } 1=0.40 \\
& \text { size } 2=0.16 \\
& \text { size } 3=0.02 \\
& \text { size } 4=0.26 \\
& \text { size } 5=0.16
\end{aligned}
$$

Past data

${ }^{a}$ weight of the monitoring parameter; ${ }^{\mathrm{b}}$ number of the equivalent data for non-monitoring components; ${ }^{\star}<500-1000$ ton day ${ }^{-1}$; 90 days $($ since August 15 2001, after July-August 2001 flank eruption)

Table 1. Summary of the BET_EF input information (prior models, past data and monitoring parameters) for the 2001-2005 period analyzed. The thresholds and inertia of the collected parameters are also shown.

information (Figure 1b). After the test case [Brancato et al., in press], a fifth and final session took place for the final considerations and comments. An initial dataset of 51 parameters (56, after the second session; Figure 2) was considered. By thorough examination, some parameters were seen to be clones or strongly correlated with others, hence they were included in those parameters that showed broader features. A final collection of 48 parameters was retained (Figure 2). At the moment, because of some difficulties in retrieving reliable data, only 42 out of these 48 parameters are routinely considered. Tremor data in node 1 is available only up to July 31,2001 , and in node 3 , only up to July 23 , 2001. Therefore, given the lack of more information, after these dates the relative values were set as nonanomalous.
The magnetic parameter deserves further discussion. It was set well for nodes 1 and 2, whereas it showed some incoherence for node 3 , because the expected variations were not fully supported by the data acquired. For this reason, the magnetic parameter is discarded for the present analysis, thus reducing the final dataset to 39 parameters (Table 1).

An important question was to consider the parameters according to Boolean or fuzzy approaches. Since the application is monitoring, an expression of the state of the volcano is required that is based on threshold levels of the parameters. A Boolean approach could be a crude decision because a single threshold would only distinguish between two possible states (anomalous or not anomalous).

Indeed, a system can evolve to an anomalous state 


\begin{tabular}{|c|c|c|c|}
\hline & & Boolean & Fuzzy \\
\hline \multirow{4}{*}{ 节 } & All Nodes & 25 & 26 \\
\hline & Node 1 & 10 & 14 \\
\hline & Node 2 & 7 & 7 \\
\hline & Node 3 & 8 & 5 \\
\hline \multirow{4}{*}{ 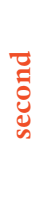 } & All Nodes & 30 & 26 \\
\hline & Node 1 & 11 & 14 \\
\hline & Node 2 & 10 & 7 \\
\hline & Node 3 & 9 & 5 \\
\hline \multirow{5}{*}{ 苛 } & All Nodes & 24 & 24 \\
\hline & Node 1 & 8 & 11 \\
\hline & Node 2 & 10 & 7 \\
\hline & Node 3 & 6 & 6 \\
\hline & All Nodes & 27 & 21 \\
\hline \multirow{3}{*}{ 己릴 } & Node 1 & 9 & 10 \\
\hline & Node 2 & 11 & 6 \\
\hline & Node 3 & 7 & 5 \\
\hline \multirow{4}{*}{$\sum_{\&}^{E}$} & All Nodes & 8 & 24 \\
\hline & Node 1 & 5 & 12 \\
\hline & Node 2 & 3 & 10 \\
\hline & Node 3 & 0 & 12 \\
\hline
\end{tabular}

Table 2. Numerical divisions of the monitoring parameters elicited, according to the Boolean or fuzzy approaches. Orange box results as obtained after the fifth elicitation session. Note: the fuzzy approach for all of the parameters for node 3 (eruption/ no eruption).

gradually, rather than by overcoming one specific value of a monitoring measure. Furthermore, the threshold level might be considered to be strongly subjective, thus affecting the results. These aspects can be refined through a fuzzy approach when considering the parameters. This approach can tune the estimated probabilities at each node, according to the considered error function implemented in the code. A result of note is that all of the parameters used for node 3 follow a fuzzy behavior (Table 2).

The meaning and the duration of the inertia times that are associated to each specific monitored parameter were also elicited. 'Inertia' is the time period starting from the exceeding of the threshold during which the effects elicited on the anomalous state of the volcano persist. By using a boxcarshaped inertia time window, the contribution of any anomalous parameter to the definition of the node probabilities will completely vanish after expiration of the inertia time (Table 1). Indeed, each inertia window is applied to the whole time series of all of the elicited monitoring parameters, to fix the maximum value for the code application (or a minimum, according to the trend of the relative parameter).
Thresholds were set by consideration of the prior experience of the researchers, as well as of the temporal trend of the parameter considered. Additionally, after the performed test case [Brancato et al., in press] and the relative feedback process, most of the already set thresholds were updated for the period under investigation (2001-2005), particularly for node 3 . This is the case for the seismic activity, the ground deformation, and the gravity measurements. As can be seen in Table 1, most of the fuzzy parameters have still been elicited as an increasing trend, according to the relevant literature.

Conversely, and again with a fuzzy approach, $\mathrm{SO}_{2}$ emissions have been elicited as a decreasing trend in node 1 , as well as $\mathrm{CO}_{2}$ emissions in node 3 (Table 1). Therefore, as in the former test case [Brancato et al., in press], the roles of soil $\mathrm{CO}_{2}$ and crater $\mathrm{SO}_{2}$ emissions deserve further explanation.

The degassing style of Mount Etna showed new and remarkable features after the July-August 2001 flank eruption [Caltabiano et al. 1994]. There were diffuse $\mathrm{CO}_{2}$ emissions at station P39 (see Figure 2) [Brancato et al., in press] which were generally lower and were characterized by short-lived spikelike anomalies. Conversely, $\mathrm{CO}_{2}$ emissions at site P78 (see Figure 2) [Brancato et al., in press] were higher, especially after the end of the 2002-2003 flank eruption, and they were also characterized by a spike-like behavior. Increases in the soil $\mathrm{CO}_{2}$ flux at this site were normally followed by marked decreases, down to almost zero levels, when the magma made its way up to the surface in the days preceding the eruptions, or accompanied intrusions to shallower levels. Crater $\mathrm{SO}_{2}$ fluxes were much lower during the inter-eruptive periods, although they generally showed the same temporal behavior as pre2001 data (i.e. marked decreases about one month before the eruptions, followed by increasing trends until the eruptions).

It is unlikely that the differences observed between the pre-2001 and post-2001 gas emission patterns were due to changes in the ways the magmatic gases were exsolved from the magma at depth. In the present study, therefore, we use new order relations and thresholds that better describe the degassing features of Mount Etna during the period studied (Table 1). In addition, the thresholds for $\mathrm{SO}_{2}$ were set to different values after the 2001 flank eruption (Table 1).

For the petrological monitoring, at node 2, we considered the 'juvenile material' parameter to indicate material that derived directly from the magma that reached the surface, which can consist of both sideromelane and tachylite.

\section{Setting the Bayesian Event Tree for Eruption Forecasting code for Mount Etna volcano}

Following the basic principle that any model and input data used to set up the code are selected by considering the principles of simplicity and acceptance by a wide scientific community, we assume that the starting point is a state of maximum ignorance (i.e. no possibility is excluded). The probability estimates are then revised (in a Bayesian 
framework) based on the availability of robust and widely accepted models and data.

In the following, we give a brief explanation of the choices made at each node. As aforementioned, each node consists of a nonmonitoring (distinct in a-priori distribution and past likelihood data) and a monitoring component.

For node 1 (unrest/no unrest), no information is available for the a-priori model; then, a uniform distribution (representing maximum ignorance) is assumed. For the past data, we used the instrumental seismic catalog for Mount Etna for the period January 1978 to December 2000. In this time interval ( 23 years; 1200 weeks), we counted the number of unrest episodes (eruptive or not). Considering that noneruptive unrest episodes were roughly defined by looking at the average daily rate of earthquakes occurring on Mount Etna (on average, 3 events per day), we defined an unrest episode as when 35 earthquakes per week was reached. Based on this broad definition, we counted 26 unrest episodes with no eruptions for a total of 56 weeks. In the same period, the volcano experienced 10 flank eruptions, for a total of 133 weeks. This totals 36 unrest episodes (eruptive or not) that were spread over a period of 1047 weeks (Table 1). This last is calculated as the difference between the whole period (1200 weeks) and the total time (189 weeks) during which Mount Etna was in unrest (eruptive or not), summed to the total of 36 episodes.
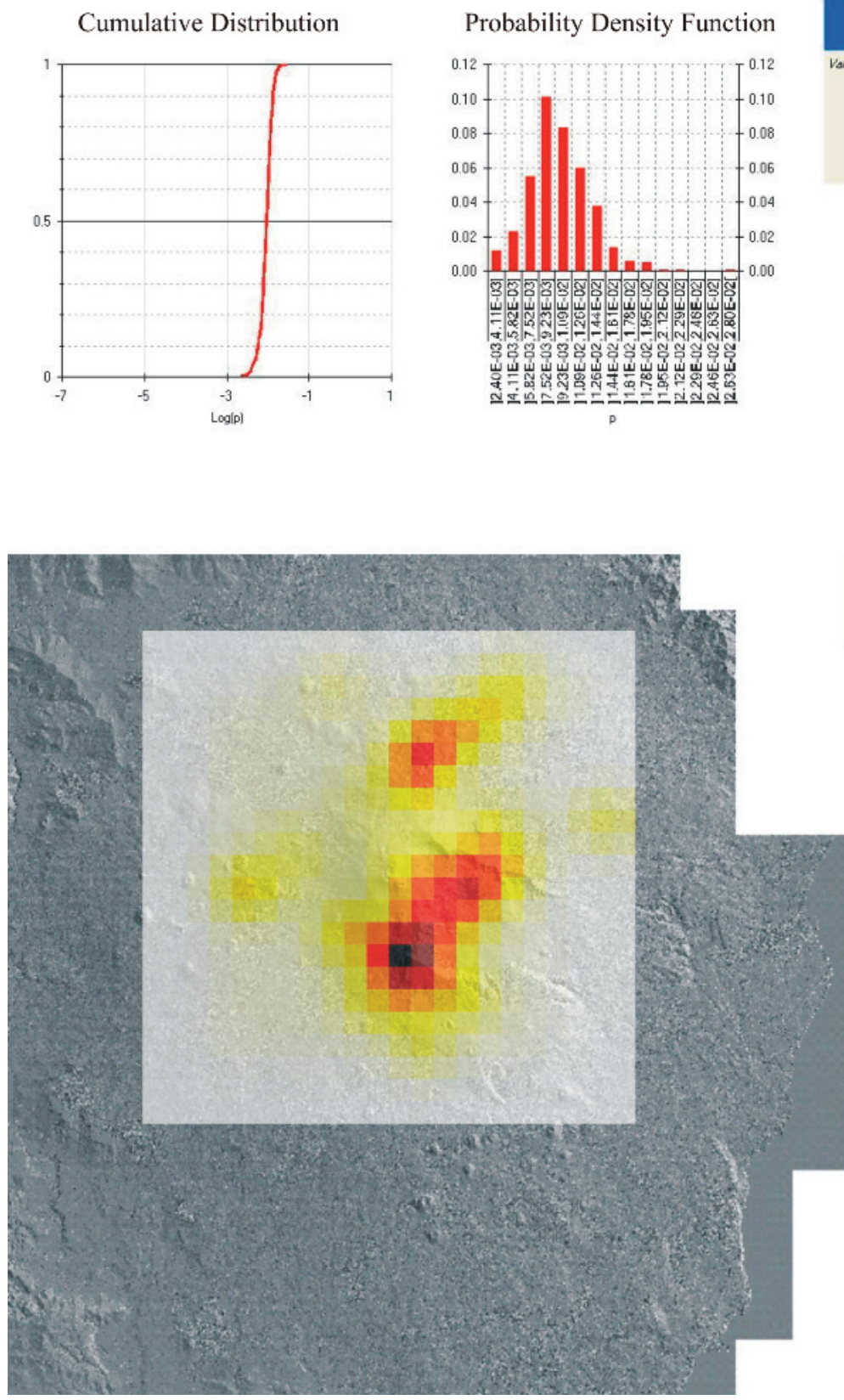

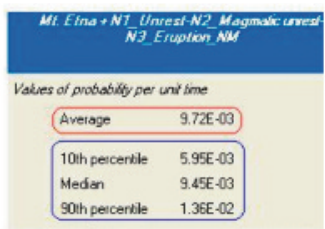

a.
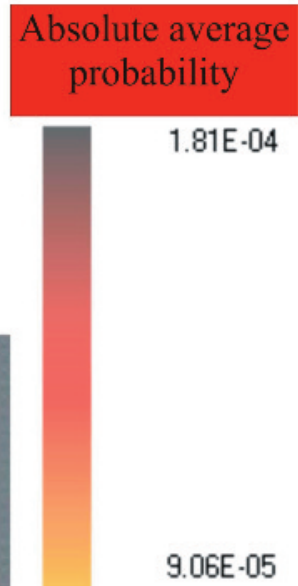

0.0

Figure 3. a) Graphic output of the BET_EF software package for the absolute probability estimate for node 3 (eruption node), when no unrest is observed. Blue rectangular box, median probability calculated for the non-monitoring component; the errors are also shown (10th and 90th percentile). Red rectangular box, average probability. b) Map showing the space-time probability of an eruptive vent opening when no unrest is observed. 
For the monitoring component, we collected 16 parameters. The relative order relations, thresholds, and inertia time windows (in days) are shown in Table 1.

For the nonmonitoring component of node 2 (magma/ no magma), a probability of magmatic unrest (an a-priori distribution), given the occurrence of an unrest, is set to $95 \%$ (as usually assumed worldwide for volcanoes such as Mount Etna; Newhall, personal communication). This value indicates that $95 \%$ of the unrest episodes are of magmatic origin. The number of equivalent data $\Lambda$ [Marzocchi et al. 2008 ] is equal to 1 , thus indicating the large uncertainty. No past data are available for this node.

For the monitoring component, a total of 12 parameters was set (Table 1). The weights are not the same for all of these parameters. Although the whole monitoring dataset can be considered as very significant for the presence of magma, a weight of 2 is assigned only to the seismic and tilt parameters (Table 1). Indeed, as they are monitored daily, these parameters are more indicative than the others that are retrieved from seasonal or occasional campaigns. No past monitored events are present.

For node 3 (eruption/ no eruption), no information is available for the a-priori distribution; hence, a uniform model is assumed. For past data, considering this period of January 1978 to December 2000, 10 unrest episodes of the 36 were marked by eruptions (see node 1 ; Table 1 ).

For the monitoring component, we consider 11 parameters (Table 1). As for node 2, a weight of 1 is assigned by default, whereas a weight of 2 highlights the strong eruption forecasting capacity of the seismic and tilt parameters (Table 1).

For the vent location (node 4), we provide the same graphical framework as proposed for the previous test case (Figure 3b) [Brancato et al., in press].

Taking into account past vent locations and fracture location datasets, in particular based on the flank eruptive history of the volcano during the last 400 years [Project V3Lava 2010], we considered a grid area that was divided into 484 squared cells $\left(22 \times 22\right.$; each cell has a surface of $1 \mathrm{~km}^{2}$; Figure 3b). Cells \#231, \#232, \#253 and \#254 enclose the summit crater area.

Mount Etna has experienced 43 flank eruptive episodes over the last 400 years [Project V3-Lava 2010]. Table 3 summarizes these data, as distinct per duration $(<45$ or $>45$ days) and volume $\left(1-30,30-100,>10010^{6} \mathrm{~m}^{3}\right)$ of erupted lava.

A vent opening probability must be assigned to each cell. Considering the geographical distribution of the known 43 flank eruptions (Figure 4), we discriminate the case when one or more vents are located inside a cell. Thus, probabilities of $3 \%, 8 \%$ and $12 \%$ are arbitrarily assigned if a cell has one, two or three (one case) historical vents within it, respectively. In addition, it is evident that the eastern slope of the volcano is more active than the western slope (Figure 4). To take this into account, we introduce the so-called flank factor; namely, a value that 'weights' the different flank activities accordingly. Values of $66 \%$ (for the eastern flank) and 33\% (for the western flank) multiply the above probabilities, respectively. Finally, to normalize the probability density function, we assign a value of $0.1 \%$ for those cells surrounding the summit area, and $0.01 \%$ moving towards the external margins of the grid, to reach the minimum of $0.005 \%$ along the borders.

The counts of past eruptive vents inside each cell are used to shape the likelihood function. No specific monitoring parameters are set for this node, but all of the parameters set for the preceding nodes might be suitable to assess the future vent opening probability [Marzocchi et al. 2008]. In particular, we considered seismic activity and tilt recording sets in nodes 1,2 and 3 as the most significant for the next vent opening, as these are especially localized.

For the final node 5 , the theoretical approach has shown to date that no monitoring parameter can provide insights into the size and style of an impending eruption [e.g. Sandri

\begin{tabular}{|c|c|c|c|c|}
\hline & \multicolumn{4}{|c|}{ Volume $\left(\mathbf{1 0}^{6} \mathbf{m}^{3}\right)$} \\
\hline \multirow{4}{*}{ Duration (days) } & & $1-30$ & $30-100$ & $>100$ \\
\cline { 2 - 5 } & $<45$ & $17(40 \%)$ & $7(16 \%)$ & $0(0 \%)$ \\
& & Size 1 & Size 2 & $==$ \\
\cline { 2 - 5 } & $>45$ & $1(2 \%)$ & $10(23 \%)$ & $8(19 \%)$ \\
& & Size 3 & Size 4 & Size 5 \\
\hline
\end{tabular}

Table 3. Double entrance (duration of eruption; volume of erupted lava) table of data representing the 43 flank eruptions over the last 400 years that occurred on Mount Etna volcano [data from Project V3-Lava 2010].

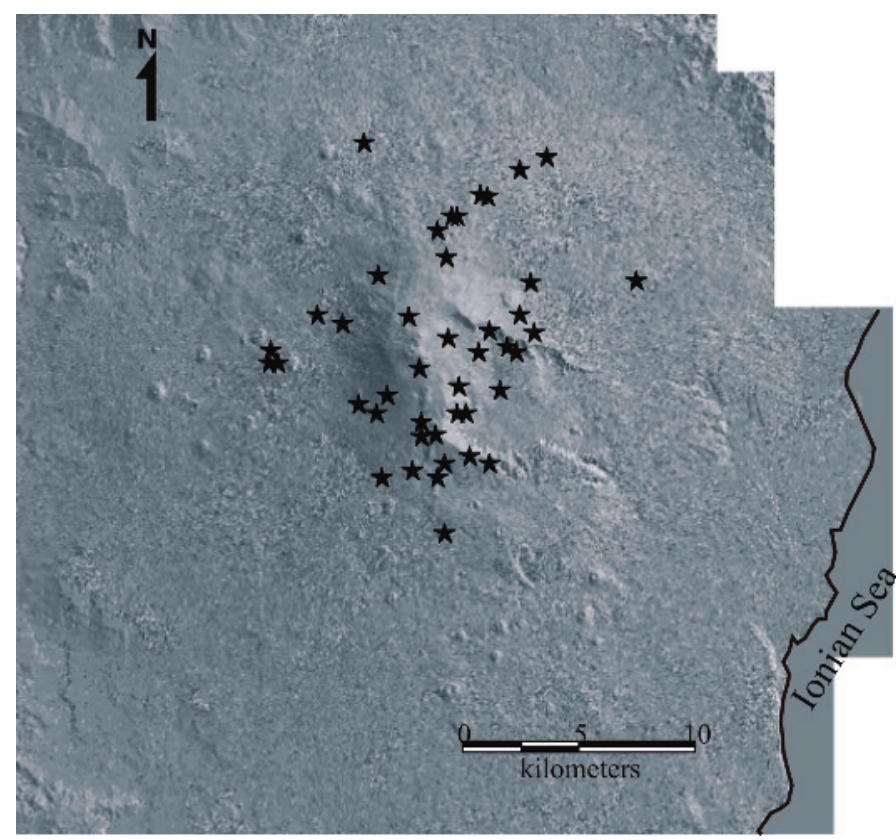

Figure 4. Location of the vents (black stars) of the flank eruptions that occurred for Mount Etna over the last 400 years [data from Project V3Lava 2010]. Thin black line, eastern coast of Sicily. 
et al. 2004]. Due to the lack of detailed information, for the a-priori model, we simply identified five classes with no zero probability value (from size 1 to size 5), by considering only the 43 flank eruptions that have occurred for Mount Etna volcano over the last 400 years (Tables 1 and 3). Again, the relative counts are used to shape the likelihood function at node 5 (Tables 1 and 3 ).

\section{Results}

The probability estimates are based on both nonmonitoring components (a-priori models and past data) and monitoring parameters.

Considering only the nonmonitoring components provides forecasting that is associated with no observed unrest. On the contrary, using the monitoring parameters,

\begin{tabular}{|c|c|c|c|}
\hline Date & Node 1 & Node 2 & Node 3 \\
\hline $20 / 04 / 2001$ & $100 \%$ & $94.8 \%$ & $52.6 \%$ \\
\hline $21 / 04 / 2001$ & $100 \%$ & $93.7 \%$ & $45.5 \%$ \\
\hline $22 / 04 / 2001$ & $100 \%$ & $95.6 \%$ & $63.0 \%$ \\
\hline $23 / 04 / 2001$ & $100 \%$ & $95.0 \%$ & $43.0 \%$ \\
\hline $07 / 05 / 2001$ & $100 \%$ & $96.3 \%$ & $63.0 \%$ \\
\hline $08 / 05 / 2001$ & $100 \%$ & $95.2 \%$ & $43.5 \%$ \\
\hline $09 / 05 / 2001$ & $100 \%$ & $96.2 \%$ & $73.4 \%$ \\
\hline $10 / 05 / 2001$ & $100 \%$ & $95.5 \%$ & $44.9 \%$ \\
\hline $04 / 06 / 2001$ & $100 \%$ & $94.0 \%$ & $43.7 \%$ \\
\hline $05 / 06 / 2001$ & $100 \%$ & $95.5 \%$ & $43.9 \%$ \\
\hline $06 / 06 / 2001$ & $100 \%$ & $95.9 \%$ & $64.5 \%$ \\
\hline $07 / 06 / 2001$ & $100 \%$ & $94.7 \%$ & $73.2 \%$ \\
\hline $08 / 06 / 2001$ & $100 \%$ & $95.5 \%$ & $61.8 \%$ \\
\hline $09 / 06 / 2001$ & $100 \%$ & $95.0 \%$ & $73.0 \%$ \\
\hline $10 / 06 / 2001$ & $100 \%$ & $94.9 \%$ & $61.8 \%$ \\
\hline $11 / 06 / 2001$ & $100 \%$ & $94.9 \%$ & $73.9 \%$ \\
\hline $12 / 06 / 2001$ & $100 \%$ & $96.4 \%$ & $62.5 \%$ \\
\hline $13 / 06 / 2001$ & $100 \%$ & $96.9 \%$ & $73.6 \%$ \\
\hline $14 / 06 / 2001$ & $100 \%$ & $96.6 \%$ & $44.7 \%$ \\
\hline $15 / 06 / 2001$ & $100 \%$ & $96.0 \%$ & $75.1 \%$ \\
\hline $16 / 06 / 2001$ & $100 \%$ & $96.0 \%$ & $44.4 \%$ \\
\hline $17 / 06 / 2001$ & $100 \%$ & $95.5 \%$ & $73.5 \%$ \\
\hline $18 / 06 / 2001$ & $100 \%$ & $94.2 \%$ & $45.8 \%$ \\
\hline $19 / 06 / 2001$ & $100 \%$ & $95.2 \%$ & $73.9 \%$ \\
\hline $20 / 06 / 2001$ & $100 \%$ & $95.3 \%$ & $44.4 \%$ \\
\hline $21 / 06 / 2001$ & $100 \%$ & $95.4 \%$ & $63.2 \%$ \\
\hline $22 / 06 / 2001$ & $100 \%$ & $95.1 \%$ & $74.6 \%$ \\
\hline $23 / 06 / 2001$ & $100 \%$ & $96.4 \%$ & $44.7 \%$ \\
\hline $24 / 06 / 2001$ & $100 \%$ & $95.1 \%$ & $72.9 \%$ \\
\hline $25 / 06 / 2001$ & $100 \%$ & $94.1 \%$ & $43.8 \%$ \\
\hline $26 / 06 / 2001$ & $100 \%$ & $95.3 \%$ & $45.6 \%$ \\
\hline $27 / 06 / 2001$ & $100 \%$ & $94.7 \%$ & $72.9 \%$ \\
\hline $28 / 06 / 2001$ & $100 \%$ & $96.4 \%$ & $62.9 \%$ \\
\hline $29 / 06 / 2001$ & $100 \%$ & $95.4 \%$ & $63.8 \%$ \\
\hline $30 / 06 / 2001$ & $100 \%$ & $95.5 \%$ & $75.3 \%$ \\
\hline $01 / 07 / 2001$ & $100 \%$ & $95.2 \%$ & $45.3 \%$ \\
\hline $02 / 07 / 2001$ & $100 \%$ & $95.3 \%$ & $46.2 \%$ \\
\hline $03 / 07 / 2001$ & $100 \%$ & $95.6 \%$ & $46.3 \%$ \\
\hline $04 / 07 / 2001$ & $100 \%$ & $96.0 \%$ & $74.5 \%$ \\
\hline $05 / 07 / 2001$ & $100 \%$ & $96.2 \%$ & $44.9 \%$ \\
\hline $06 / 07 / 2001$ & $100 \%$ & $96.1 \%$ & $46.0 \%$ \\
\hline $07 / 07 / 2001$ & $100 \%$ & $96.0 \%$ & $74.9 \%$ \\
\hline
\end{tabular}

\begin{tabular}{|c|c|c|c|}
\hline Date & Node 1 & Node 2 & Node 3 \\
\hline $08 / 07 / 2001$ & $100 \%$ & $96.8 \%$ & $46.9 \%$ \\
\hline $09 / 07 / 2001$ & $100 \%$ & $94.9 \%$ & $63.4 \%$ \\
\hline $10 / 07 / 2001$ & $100 \%$ & $95.3 \%$ & $45.4 \%$ \\
\hline $11 / 07 / 2001$ & $100 \%$ & $95.5 \%$ & $47.1 \%$ \\
\hline $12 / 07 / 2001$ & $100 \%$ & $97.3 \%$ & $90.7 \%$ \\
\hline $13 / 07 / 2001$ & $100 \%$ & $96.9 \%$ & $94.9 \%$ \\
\hline $14 / 07 / 2001$ & $100 \%$ & $98.7 \%$ & $93.5 \%$ \\
\hline $15 / 07 / 2001$ & $100 \%$ & $97.5 \%$ & $94.3 \%$ \\
\hline $16 / 07 / 2001$ & $100 \%$ & $97.3 \%$ & $93.1 \%$ \\
\hline $17 / 07 / 2001$ & $100 \%$ & $96.7 \%$ & $92.6 \%$ \\
\hline $18 / 07 / 2001$ & $100 \%$ & $97.5 \%$ & $88.4 \%$ \\
\hline $19 / 07 / 2001$ & $100 \%$ & $96.8 \%$ & $90.4 \%$ \\
\hline $20 / 07 / 2001$ & $100 \%$ & $97.4 \%$ & $89.8 \%$ \\
\hline $21 / 07 / 2001$ & $100 \%$ & $96.8 \%$ & $87.9 \%$ \\
\hline $22 / 07 / 2001$ & $100 \%$ & $97.0 \%$ & $89.2 \%$ \\
\hline $23 / 07 / 2001$ & $100 \%$ & $97.2 \%$ & $89.0 \%$ \\
\hline $24 / 07 / 2001$ & $100 \%$ & $97.0 \%$ & $89.1 \%$ \\
\hline $25 / 07 / 2001$ & $100 \%$ & $96.2 \%$ & $88.0 \%$ \\
\hline $26 / 07 / 2001$ & $100 \%$ & $97.2 \%$ & $89.0 \%$ \\
\hline $27 / 07 / 2001$ & $100 \%$ & $97.4 \%$ & $88.7 \%$ \\
\hline $28 / 07 / 2001$ & $100 \%$ & $96.7 \%$ & $89.5 \%$ \\
\hline $29 / 07 / 2001$ & $100 \%$ & $97.2 \%$ & $88.7 \%$ \\
\hline $30 / 07 / 2001$ & $100 \%$ & $96.6 \%$ & $89.1 \%$ \\
\hline $31 / 07 / 2001$ & $100 \%$ & $97.4 \%$ & $88.3 \%$ \\
\hline $01 / 08 / 2001$ & $100 \%$ & $95.8 \%$ & $88.7 \%$ \\
\hline $02 / 08 / 2001$ & $100 \%$ & $97.8 \%$ & $91.3 \%$ \\
\hline $03 / 08 / 2001$ & $100 \%$ & $96.9 \%$ & $91.2 \%$ \\
\hline $04 / 08 / 2001$ & $100 \%$ & $96.9 \%$ & $90.0 \%$ \\
\hline $05 / 08 / 2001$ & $100 \%$ & $96.7 \%$ & $91.8 \%$ \\
\hline $06 / 08 / 2001$ & $100 \%$ & $97.7 \%$ & $91.9 \%$ \\
\hline $07 / 08 / 2001$ & $100 \%$ & $97.4 \%$ & $92.0 \%$ \\
\hline $08 / 08 / 2001$ & $100 \%$ & $97.5 \%$ & $93.6 \%$ \\
\hline $09 / 08 / 2001$ & $100 \%$ & $97.5 \%$ & $92.5 \%$ \\
\hline $10 / 08 / 2001$ & $100 \%$ & $97.0 \%$ & $89.3 \%$ \\
\hline $11 / 08 / 2001$ & $100 \%$ & $97.0 \%$ & $89.6 \%$ \\
\hline $12 / 08 / 2001$ & $100 \%$ & $96.6 \%$ & $91.2 \%$ \\
\hline $13 / 08 / 2001$ & $100 \%$ & $96.2 \%$ & $89.1 \%$ \\
\hline $07 / 10 / 2002$ & $100 \%$ & $94.0 \%$ & $72.2 \%$ \\
\hline $08 / 10 / 2002$ & $100 \%$ & $94.6 \%$ & $72.7 \%$ \\
\hline $09 / 10 / 2002$ & $100 \%$ & $93.4 \%$ & $73.6 \%$ \\
\hline $10 / 10 / 2002$ & $100 \%$ & $94.3 \%$ & $74.8 \%$ \\
\hline $11 / 10 / 2002$ & $100 \%$ & $93.4 \%$ & $74.3 \%$ \\
\hline
\end{tabular}

\begin{tabular}{|c|c|c|c|}
\hline Date & Node 1 & Node 2 & Node 3 \\
\hline $12 / 10 / 2002$ & $100 \%$ & $92.6 \%$ & $74.2 \%$ \\
\hline $13 / 10 / 2002$ & $100 \%$ & $94.7 \%$ & $74.0 \%$ \\
\hline $14 / 10 / 2002$ & $100 \%$ & $94.0 \%$ & $75.0 \%$ \\
\hline $15 / 10 / 2002$ & $100 \%$ & $94.8 \%$ & $74.1 \%$ \\
\hline $16 / 10 / 2002$ & $100 \%$ & $95.0 \%$ & $74.7 \%$ \\
\hline $17 / 10 / 2002$ & $100 \%$ & $94.1 \%$ & $77.0 \%$ \\
\hline $18 / 10 / 2002$ & $100 \%$ & $94.5 \%$ & $77.1 \%$ \\
\hline $19 / 10 / 2002$ & $100 \%$ & $94.9 \%$ & $78.1 \%$ \\
\hline $20 / 10 / 2002$ & $100 \%$ & $93.9 \%$ & $75.8 \%$ \\
\hline $21 / 10 / 2002$ & $100 \%$ & $95.3 \%$ & $76.1 \%$ \\
\hline $22 / 10 / 2002$ & $100 \%$ & $93.8 \%$ & $76.0 \%$ \\
\hline $23 / 10 / 2002$ & $100 \%$ & $95.2 \%$ & $77.6 \%$ \\
\hline $24 / 10 / 2002$ & $100 \%$ & $93.5 \%$ & $76.6 \%$ \\
\hline $25 / 10 / 2002$ & $100 \%$ & $94.9 \%$ & $75.1 \%$ \\
\hline $26 / 10 / 2002$ & $100 \%$ & $96.4 \%$ & $80.9 \%$ \\
\hline $27 / 10 / 2002$ & $100 \%$ & $96.2 \%$ & $95.2 \%$ \\
\hline $28 / 10 / 2002$ & $100 \%$ & $96.0 \%$ & $91.3 \%$ \\
\hline $29 / 10 / 2002$ & $100 \%$ & $95.7 \%$ & $85.4 \%$ \\
\hline $30 / 10 / 2002$ & $100 \%$ & $96.0 \%$ & $85.6 \%$ \\
\hline $31 / 10 / 2002$ & $100 \%$ & $96.2 \%$ & $83.7 \%$ \\
\hline $01 / 11 / 2002$ & $100 \%$ & $95.6 \%$ & $84.9 \%$ \\
\hline $02 / 11 / 2002$ & $100 \%$ & $95.6 \%$ & $86.8 \%$ \\
\hline $03 / 11 / 2002$ & $100 \%$ & $95.2 \%$ & $85.4 \%$ \\
\hline $04 / 11 / 2002$ & $100 \%$ & $95.4 \%$ & $86.3 \%$ \\
\hline $05 / 11 / 2002$ & $100 \%$ & $95.3 \%$ & $87.1 \%$ \\
\hline $06 / 11 / 2002$ & $100 \%$ & $96.1 \%$ & $89.7 \%$ \\
\hline $07 / 11 / 2002$ & $100 \%$ & $95.1 \%$ & $90.3 \%$ \\
\hline $08 / 11 / 2002$ & $100 \%$ & $94.9 \%$ & $89.7 \%$ \\
\hline $09 / 11 / 2002$ & $100 \%$ & $95.3 \%$ & $87.9 \%$ \\
\hline $10 / 11 / 2002$ & $100 \%$ & $95.6 \%$ & $88.6 \%$ \\
\hline $11 / 11 / 2002$ & $100 \%$ & $93.6 \%$ & $89.8 \%$ \\
\hline $06 / 09 / 2004$ & $100 \%$ & $94.8 \%$ & $29.7 \%$ \\
\hline $07 / 09 / 2004$ & $100 \%$ & $94.6 \%$ & $28.1 \%$ \\
\hline $08 / 09 / 2004$ & $100 \%$ & $94.1 \%$ & $28.6 \%$ \\
\hline $09 / 09 / 2004$ & $100 \%$ & $94.5 \%$ & $28.3 \%$ \\
\hline $10 / 09 / 2004$ & $100 \%$ & $94.3 \%$ & $29.3 \%$ \\
\hline $11 / 09 / 2004$ & $100 \%$ & $95.6 \%$ & $27.6 \%$ \\
\hline $12 / 09 / 2004$ & $100 \%$ & $94.8 \%$ & $28.6 \%$ \\
\hline $13 / 09 / 2004$ & $100 \%$ & $93.9 \%$ & $29.0 \%$ \\
\hline
\end{tabular}

Table 4. Average probability values as estimated for nodes 1 (absolute estimates), 2 (conditional estimates) and 3 (conditional estimates). Values only refer to daily rate runs (see text for details). 
we can estimate probabilities that are usefully associated with significant variations in the volcanic phenomena on a time scale that is comparable to the fixed time window forecast (one week, in our case). Accordingly, we ran a weekly rate along the whole time interval investigated. The model is run at a daily rate when the thresholds in the monitoring database are seen to be exceeded (April 20-23, 2001; June 5 - August 18, 2001; October 7 - November 11, 2002), and for the retrospective analysis assessed before the onset of an eruption (September 7-13, 2004). Table 4 summarizes all of the probabilities estimated for these daily rate runs.

When no unrest was observed, we estimated the longterm absolute probability of eruption and vent opening. For the period investigated, the average of the absolute probability of eruption was around $1.0 \%$ per week (Figure $3 \mathrm{a})$, whereas for vent opening, the highest absolute average probability was estimated as $0.02 \%$ (Figure $3 \mathrm{~b}$ ).

The use of the monitoring component needs to be considered for the short-term eruption forecasting.

We focused our attention on the probabilities for unrest (node 1), relative magma involvement (node 2), and eruption (node 3). Our results, as estimated year by year, are presented independent of the occurrence of an eruption.

The probabilities for vent location (node 4) and size of eruption (node 5) are only analyzed for the flank eruptions that occurred in July-August 2001 and from October 2002 to January 2003, because the volcano-tectonic data was suitable.

\subsection{The 2001 forecast}

From November 2000, volcanic activity occurred at Bocca Nuova that varied from explosions to effusive lava flows [Smithsonian Institution 2000]. This activity was accompanied by seismic activity and strong degassing, which was reduced after early December 2000 [Smithsonian Institution 2000].

Figure 5 a reports all of the probability estimates for the 2001 forecast (absolute values for node 1, and conditional estimates for nodes 2 and 3). From January 2001, and throughout all of that year, an absolute value of $100 \%$ for the unrest phase is computed. This is associated with the presence of at least an anomalous parameter in the dataset elicited. Indeed, tilt, $\mathrm{SO}_{2}$ and ash emission anomalies were observed over this entire year.

Node 2 shows an average conditional estimate $>95.0 \%$ for the whole of 2001 (Figure 5a). This confirms, in part, the very frequently observed involvement of magma during these unrest phases, whereas purely phreatic eruptions were rare [Branca and Del Carlo 2005].

On the contrary, at node 3 , given the more restricted inertia time window, the conditional probabilities of eruption vary according to the presence of anomalous monitoring parameters, in the range of $27.0 \%$ to $95.0 \%$ (Figure $5 \mathrm{a}$ ). A constant value $>40.0 \%$ is computed starting from January 2001, up to the middle of February 2001 (Figure 5a), due to anomalies in $\mathrm{CO}_{2}$ emission as well as ongoing volcanic activity. Indeed, resumed summit volcanic activity was observed from the first ten days in January 2001 up to the first ten days of June 2001, which included both strombolian and effusive lava flows [Smithsonian Institution 2001, Branca and Del Carlo 2005].

Starting from mid-February 2001, and over more than one month, the probability of eruption showed a sharp increase towards values $>65.0 \%$ (Figure $5 \mathrm{a}$ ). During this period, anomalies were observed in the strong $\mathrm{SO}_{2}$ and $\mathrm{CO}_{2}$ degassing. A few days afterwards, on April 20, 2001, there was an intense seismic swarm ( $>90$ volcano-tectonic earthquakes in a day), which resulted in a new and sudden increase in the probability of an eruption (52.6\%; Figure 5a). On April 22, 2001, tremor activity was added to the still occurring seismic volcano-tectonic earthquake, and the probability rose to $63.0 \%$ (Figure $5 \mathrm{a}$ ). While these strombolian and effusive lava flows were still ongoing from summit craters, no new eruptive activity was observed until early May, 2001, when there was a short-lived (for a few hours) lava fountain at the South-East Crater. This last was enhanced by anomalies in the tremor data, which thus yielded the probability of 73.4\% on May 9, 2001 (Figure 5a). After that, the probability dropped to around $40.0 \%$ until early June, 2001, with a maximum probability of $75.3 \%$ (Figure 5). Starting from June 6, 2001, new lava fountaining activity resumed at the South-East Crater, with a more regular frequency (charge and discharge episodes). These events lasted up to early July 2001 (13 lava fountains) [Behncke et al. 2006].

Starting from July 12, 2001, in the monitoring dataset there was a sudden increase in the seismic activity (more than 100 earthquakes recorded daily), as well as anomalies in the geochemical fluids, dilatation and gravity. The code response is a large jump towards probabilities $>90.0 \%$ (Figure 5); the maximum of $94.9 \%$ is estimated for July 13,2001 , when the peak of seismicity of 998 events was recorded (Figure 5). Flank activity was reported for the South-East Crater from July 17, 2001 [Smithsonian Institution 2001]; the probability estimate reached $92.6 \%$ (Figure 5) and also maintained relatively high values $(52.0 \%-76.5 \%)$ for the following months, although the eruption stopped on August 9, 2001 (Figure 5). Apart from strong degassing from summit craters, no new eruptive activity occurred until September 2001 [Smithsonian Institution 2001]. Up to the end of October 2001, the volcanic activity was very low, as it was mostly degassing, which was occasionally accompanied by ash emissions from summit vents [Smithsonian Institution 2001].

All of these observed variations in the anomalous parameters lasted up to the end of December 2001, when 

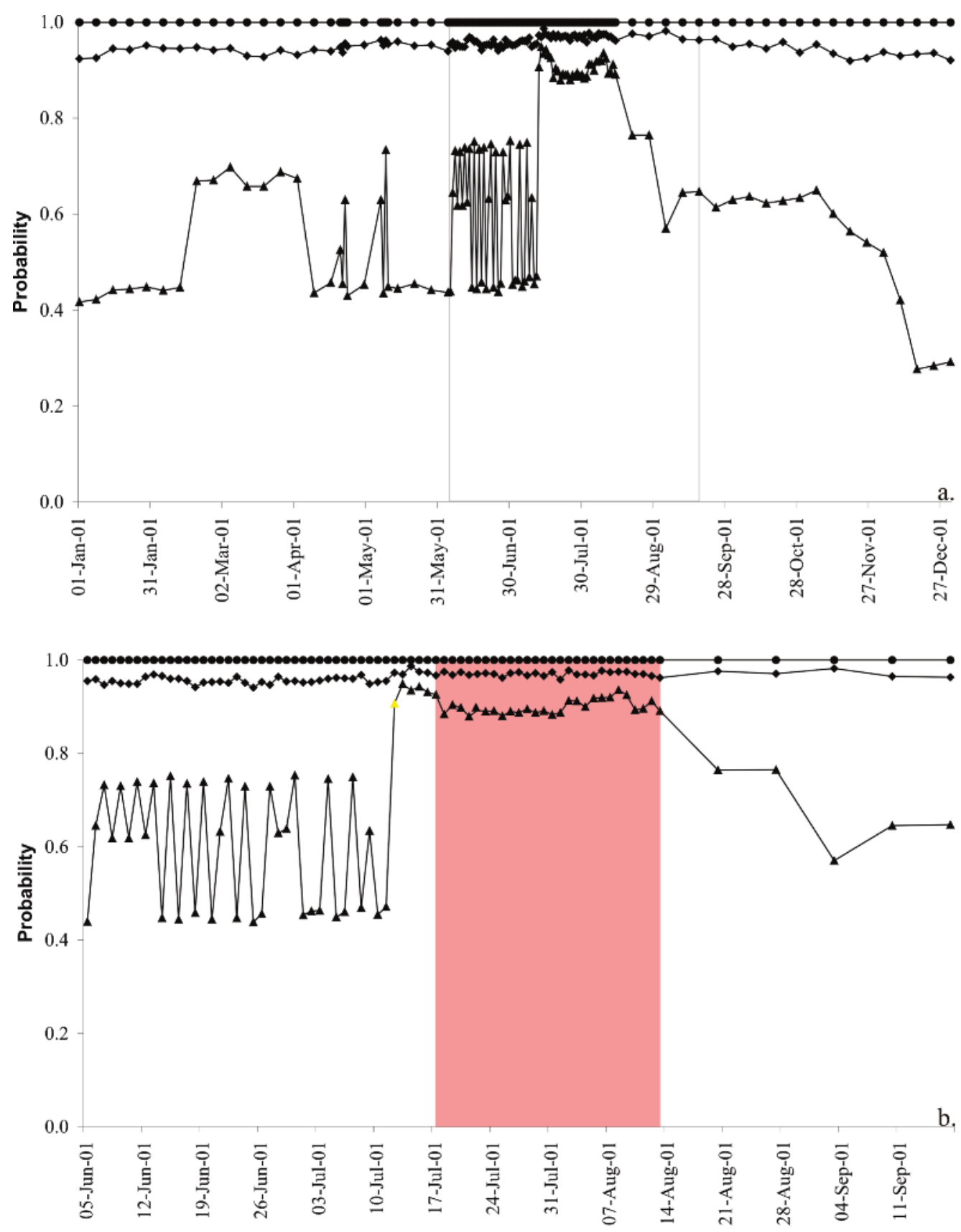

Figure 5. a) Probability estimates for the 2001 forecast at Mount Etna. Circles, absolute probability for node 1 (unrest); diamonds, conditional probability for node 2 (magmatic unrest, given an unrest); and triangles, conditional probability for node 3 (eruption, given a magmatic unrest). b) Enlargement of the probability values estimated for the period June 5 to September 17, 2001 (rectangular box in (a)). Yellow triangle, onset of the volcano-tectonic seismicity of July 12, 2001; pink box, volcanic activity of the flank eruption of July 17 to August 9, 2001.

the probability of an eruption dropped to around the background level (Figure 5a).

Shallow earthquakes (depth $<5 \mathrm{~km}$ ) is the parameter with the most significant anomaly that led to precursor activity for the July-August 2001 effusive flank episode. Thus, by considering the epicenters of the events that occurred just before the onset of this eruption, we generated maps showing the relative probabilities of vent opening inside the weekly forecast time windows (Figure 6). As the clustering along the swarm period (July12-17, 2001), the seismicity depicts the same vent location area at the south of the base of the South-East Crater, and the eventual vent site fell consistently within the highest probability zone on all of these maps (Figure 6). The maximum of $6.2 \%$ was reached on July 17, 2001, the day of the start of the eruption (Figure 6). Although within the same vent location area, the flank eruption had a complex development, with different vents opening at different heights (Figure 6).

The probabilities estimated for node 5 do not change with time, probably owing to the independence of the 

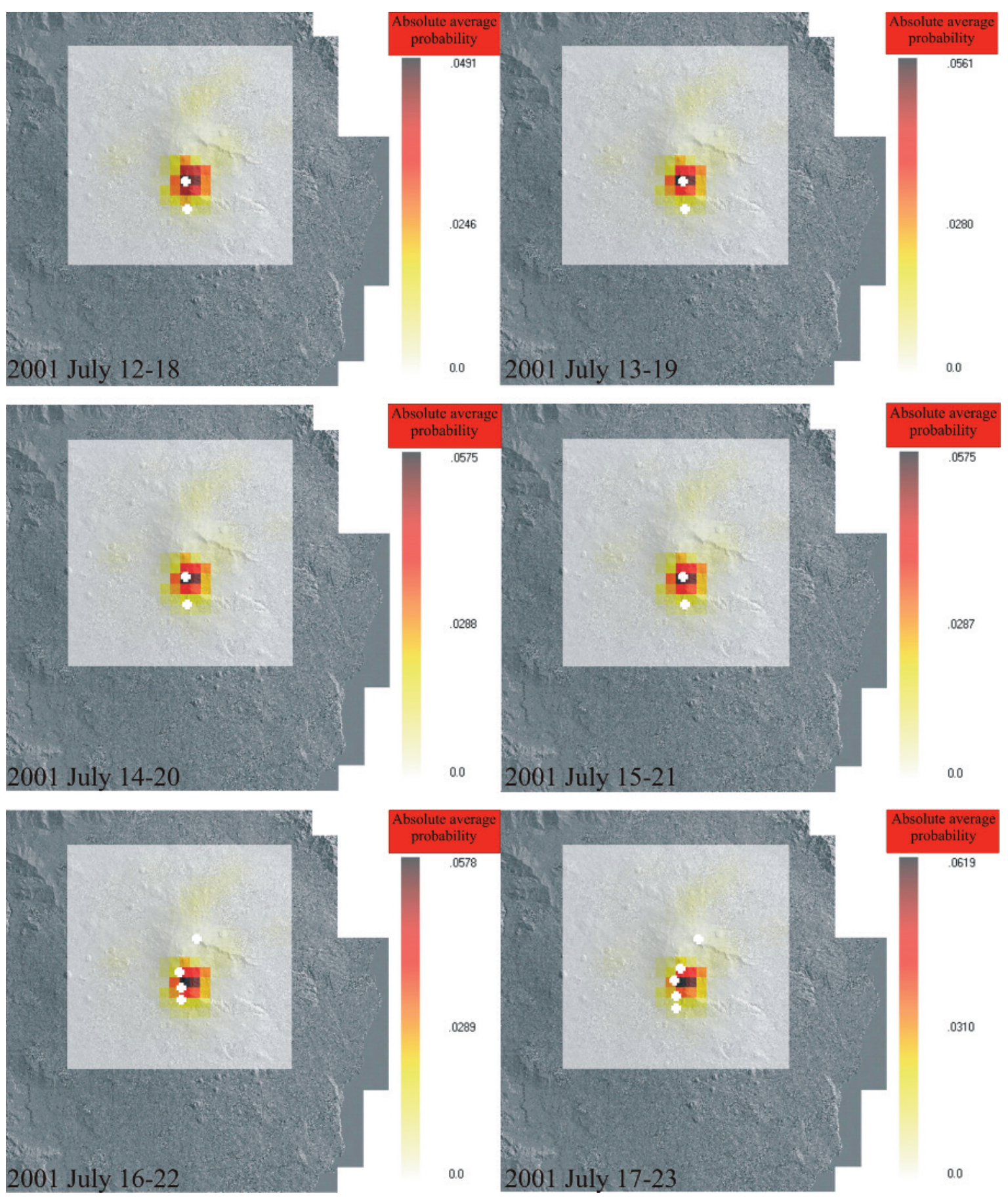

Figure 6. Maps of the probabilities of vent opening in the period July 12-23, 2001. Color scale bar (at right of each panel), average absolute probability as spread over the grid area considered in the present study. White crosses, locations of the eruptive vents that opened during the particular one week probability windows shown (see Figure $3 \mathrm{~b}$ for comparison).

monitoring data (Table 5). The most informative result is a substantial representation of the eruptive history of the volcano (for comparison, see Table 3).

\subsection{The 2002 forecast}

Throughout the whole of 2002, the probability estimates for nodes 1 and 2 maintained similar values to those of the 2001 forecast $(100 \%$ and $86.1 \%-96.6 \%$, respectively; Figure 7a). The node 1 values are due to the tilt parameter elicited. The probability of eruption (node 3) showed an increasing trend, starting from mid-February 2002 up to the last week of March 2002 (Figure 7a). The probability leveled at around $65.0 \%$ up to the last week of June 2002, after which it rose to $>75.0 \%$ (Figure $7 \mathrm{a}$ ). Then, there was an inverted decreasing trend (minimum of 59.6\%) that was estimated up to the end of August 2002 (Figure 7a). During all of these periods, a strong anomaly was observed only for $\mathrm{CO}_{2}$ emission, as a consequence of the threshold 


\begin{tabular}{|c|c|c|c|c|c|}
\hline Date & \multicolumn{5}{|c|}{ Node 5 } \\
\hline & Size 1 & Size 2 & Size 3 & Size 4 & Size 5 \\
\hline $2001 / 07 / 12$ & $20.4 \%$ & $18.9 \%$ & $17.9 \%$ & $22.9 \%$ & $19.9 \%$ \\
\hline $2001 / 07 / 13$ & $20.4 \%$ & $19.1 \%$ & $17.8 \%$ & $22.9 \%$ & $19.8 \%$ \\
\hline $2001 / 07 / 14$ & $20.4 \%$ & $19.1 \%$ & $17.8 \%$ & $22.9 \%$ & $19.8 \%$ \\
\hline $2001 / 07 / 16$ & $20.4 \%$ & $19.1 \%$ & $17.8 \%$ & $22.9 \%$ & $19.8 \%$ \\
\hline $2001 / 07 / 17$ & $20.4 \%$ & $19.1 \%$ & $17.8 \%$ & $22.9 \%$ & $19.8 \%$ \\
\hline $2001 / 07 / 18$ & $20.6 \%$ & $19.2 \%$ & $17.8 \%$ & $22.7 \%$ & $19.7 \%$ \\
\hline $2002 / 10 / 26$ & $21.4 \%$ & $18.5 \%$ & $17.6 \%$ & $24.0 \%$ & $18.5 \%$ \\
\hline $2002 / 10 / 27$ & $21.6 \%$ & $19.0 \%$ & $17.8 \%$ & $22.8 \%$ & $18.8 \%$ \\
\hline
\end{tabular}

Table 5. Average conditional probabilities estimated for node 5. Reported values refer to the flank eruptive activity that occurred for Mount Etna in July-August 2001 and from October 2002 to January 2003. elicited. The eruptive activity was very low (mostly ash and gases emission, from summit craters) or almost absent [Smithsonian Institution 2002].

After this, a new sharper increasing trend was estimated up to the end of October (maximum of $78.1 \%$; Figure $7 a$ ), during which anomalies in the gravity measurements accompanied the previous anomalous $\mathrm{CO}_{2}$ emissions. A seismic swarm started in the last hours of October 26, 2002, and initially it struck the central upper part of the volcanic edifice. During the night between October 26 and 27, 2002, the seismic activity also spread to the upper north-eastern flank of Mount Etna, with the hypocenters located at a depth of $6 \mathrm{~km}$ below sea level [Barberi et al. 2004]. The probability
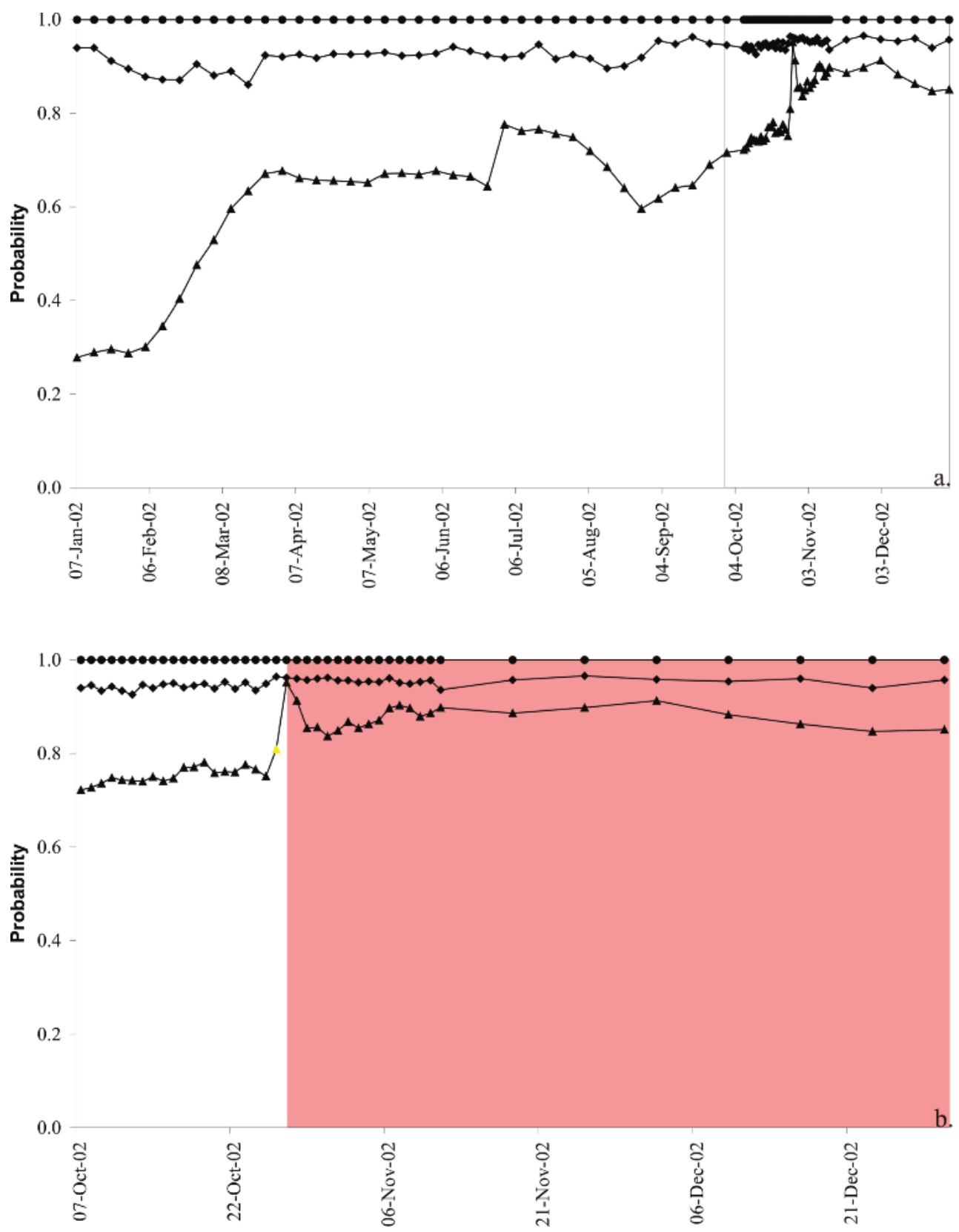

Figure 7. a) As for Figure 5a, for the 2002 forecast. b) Enlargement as for Figure 5b, for the period October 7 to December 30, 2002 (rectangular box in (a)). Yellow triangle, onset of the volcano-tectonic seismicity of October 26, 2002; pink box, volcanic activity of the flank eruption of October 27,2002 , to January 28, 2003. 


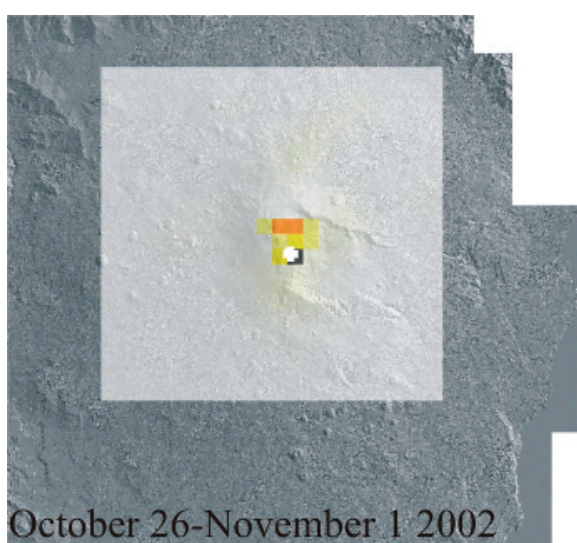

20:00-22:00

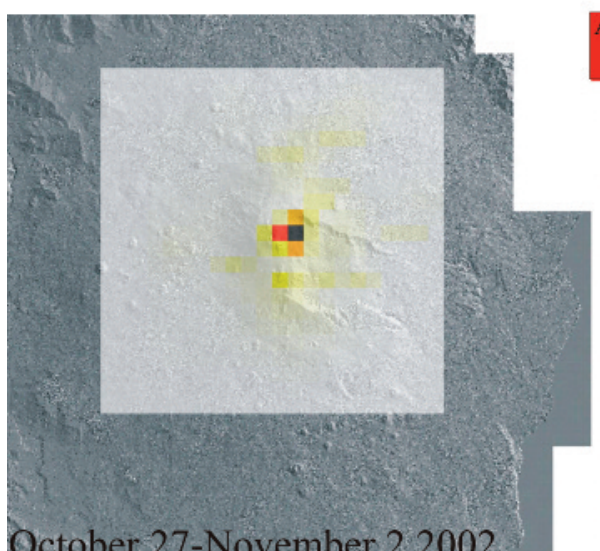
00:00-02:00

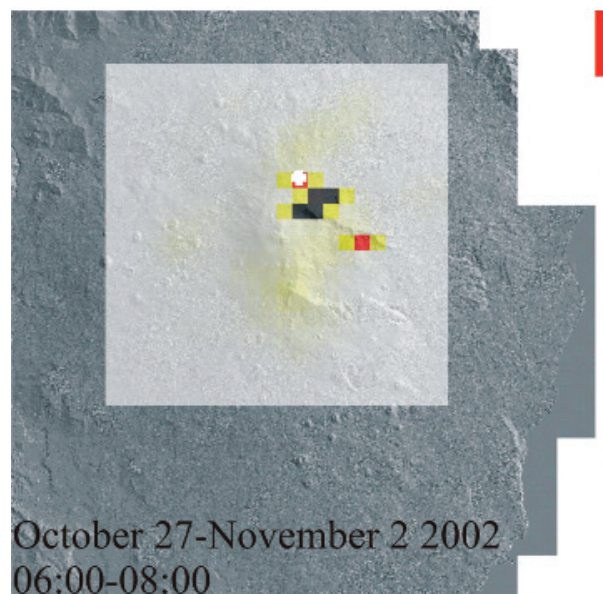

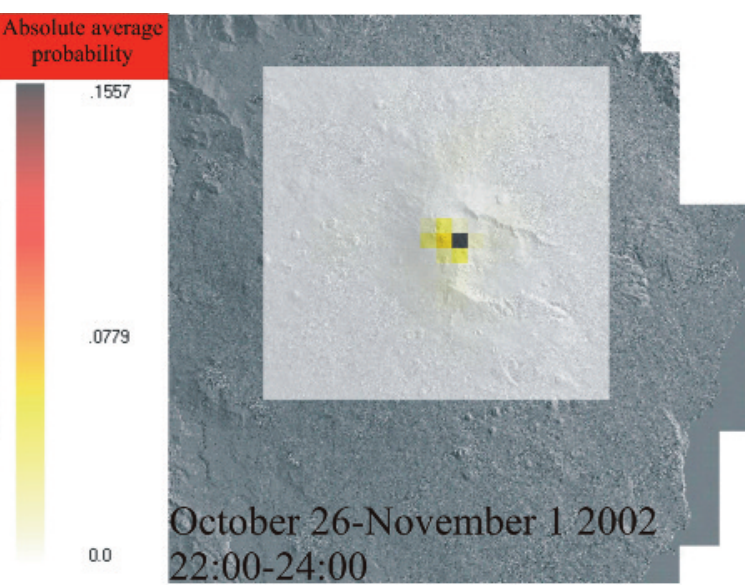

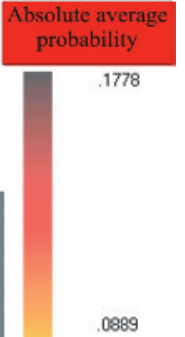

.0889

0.0
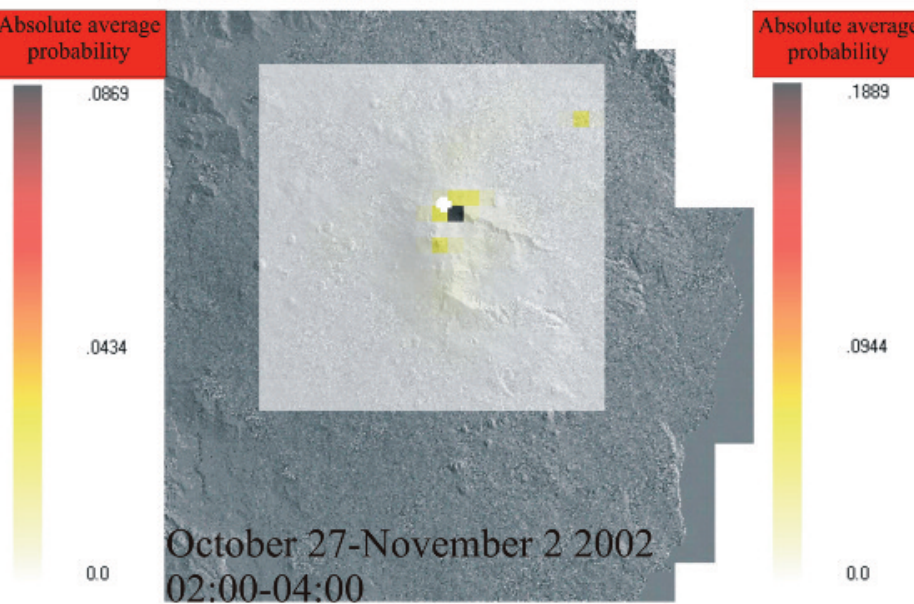

1889

.0944

0.0
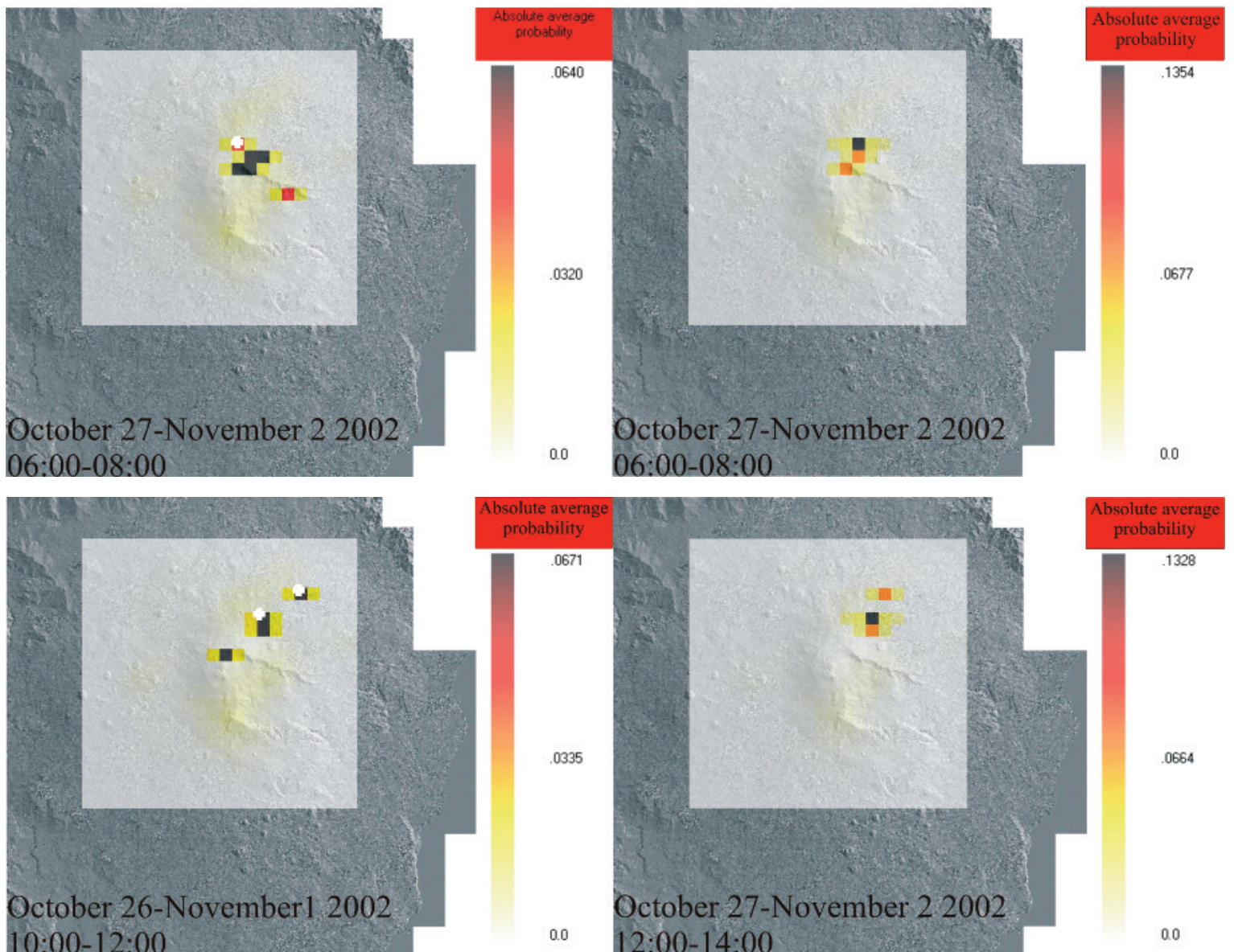

0.0

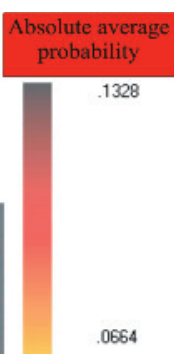

0664

0.0

Figure 8 (continues on following page). Maps showing the probabilities of vent opening for October 26-November 2, 2003 (maps generated every 2 hours; see text for details). Color scale bar (at right of each panel), as for Figure 6. White crosses, as for Figure 6 (see Figure 3b for comparison). 


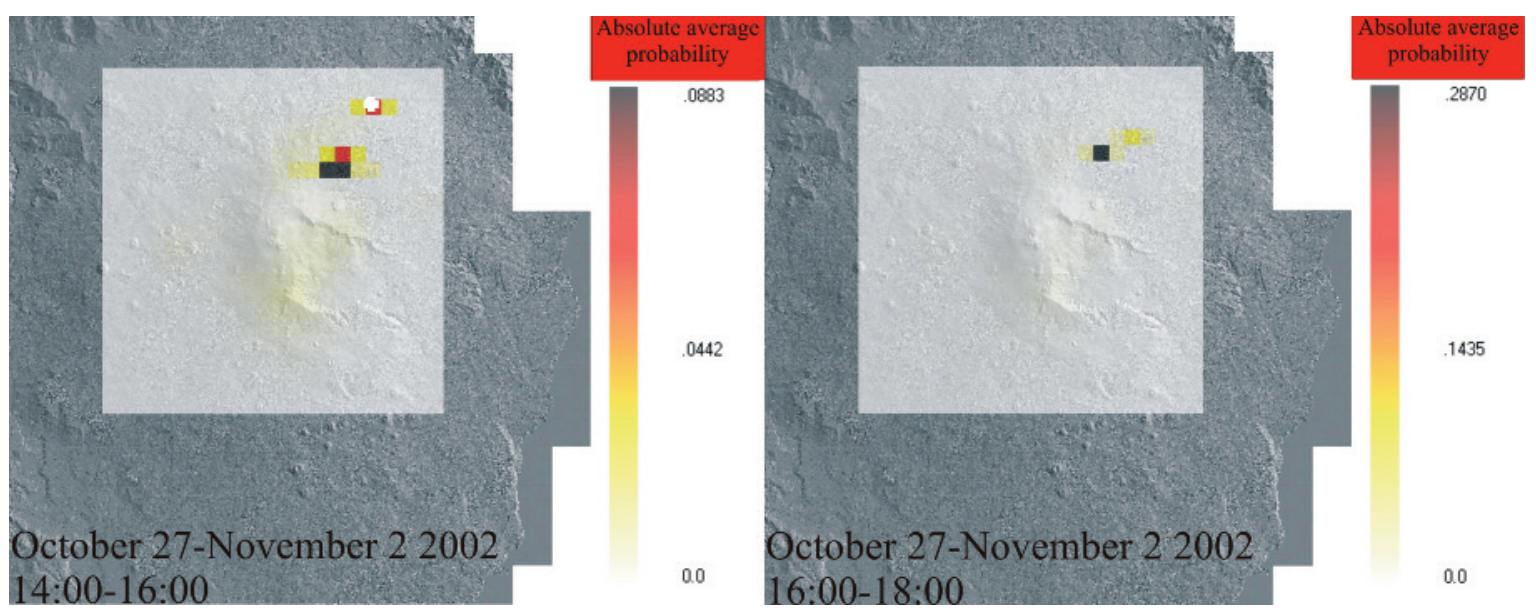

Figure 8 (continued).

of eruption jumped to $>90.0 \%$ (Figure 7 ), and new strong anomalies were observed in the tilt measurements and $\mathrm{SO}_{2}$ emissions. Indeed, starting from early September, 2002, there was strong strombolian activity at the North-East Crater [Smithsonian Institution 2002], and a relatively large lateral eruptive event was impending on Mount Etna from late on the night of October 26, 2002 [Neri et al. 2004, Monaco et al. 2005]. The flank activity stopped on January 28, 2003 [Andronico et al. 2005]. After the onset of the eruption, the probability of eruption stayed $>85.0 \%$ up to the end of December (Figure 7).

As for the July-August 2001 flank eruption, the shallow volcano-tectonic seismicity concurred in generating maps that show the relative probabilities of vent opening (node 4). Now the seismicity is considered according to the relative occurrence. Therefore, the maps were created by taking into account the shallow volcano-tectonic seismicity that occurred every two hours (at least four events). Figure 8 tracks the pattern of the vent location area within the weekly forecasting time window. No seismic activity occurred from 08:00 to $10: 00$. The maximum probability $(28.7 \%)$ was estimated on October 27, 2002, from 16:00 to 18:00. After this, the seismic activity decreased drastically.

As for the July-August 2001 flank eruption, the vent location area was spread on two different sides of the volcano, located at the south of the base of the South-East Crater, and along the north-eastern rift (Figure 8). Indeed, Neri et al. (2004) reported that two eruptive fissure systems opened on the southern and north-eastern flanks (see Figure 2 for comparison).

Again, the probabilities estimated for node 5 do not show any variations over time (Table 5).

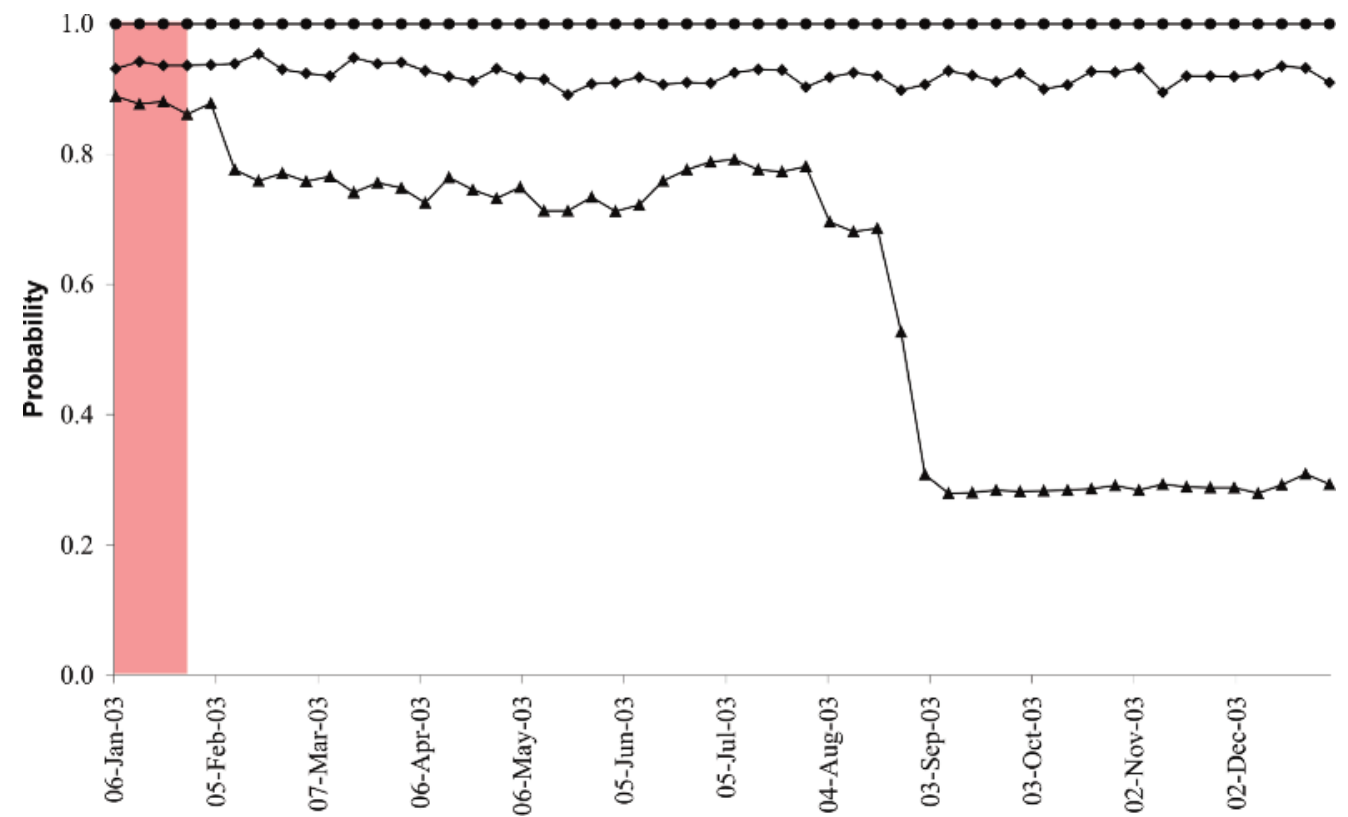

Figure 9. As for Figure 5a, for the 2003 forecast. Pink box, end of the flank eruption of October 272002 to January 28, 2003. 

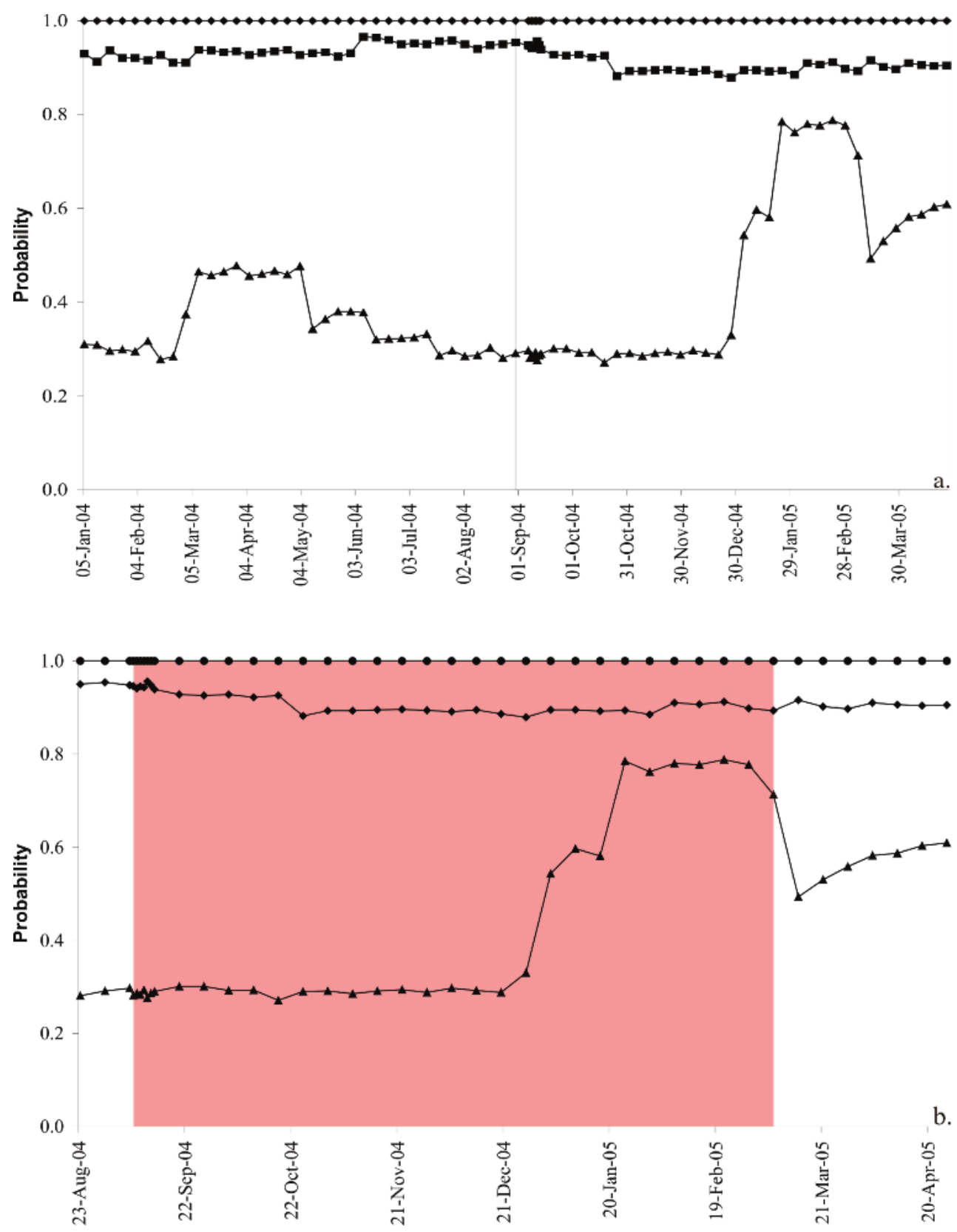

Figure 10. a) As for Figure 5a, for the January 2004 to April 2005 forecast. b) Enlargement as for Figure 5b, for the period August 23, 2004, to April 25, 2005 (rectangular box in (a)). Pink box, volcanic activity of the flank eruption of September 7, 2004, to March 8, 2005.

\subsection{The 2003 forecast}

Also for the 2003 forecast, the probability estimates for node 1 (a constant 100\%) and 2 (from 89.1\%-95.4\%) are similar to the previous years of 2001 and 2002 (Figure 9). Again, as in 2002, a constant anomaly was observed for the tilt parameter elicited for node 1.

For node 3, a high probability, as close to $90.0 \%$, is observed up to early February (Figure 9). The code reflects the end of the anomalies that were observed from early September 2002, due to the different inertia time window for the different monitoring parameters. In detail, the roles of both the $\mathrm{CO}_{2}$ and $\mathrm{SO}_{2}$ thresholds elicited were predominant (Table 1).
Starting from the first ten days of February, 2003, a slight decrease led to the probability of eruption leveling at around $75.0 \%$, up to the middle of August 2003 (Figure 9). Except for very low $\mathrm{CO}_{2}$ values inside the inertia period (down to 0 $\mathrm{g} \mathrm{m}^{-2}$ day $^{-1}$ from mid-June to mid-August 2003), no monitoring anomalies were observed. The inertia time window of the parameter completely vanished after the last ten days of August (Figure 9). As a consequence, a background level of around $28.0 \%$ was estimated up to the end of December 2003 (Figure 9).

No relevant volcanic activity occurred at Mount Etna for the whole of 2003 after the end of the flank eruption (January 28, 2003). Very minor emissions were observed at 
summit craters, which were often accompanied by vigorous or less intense gas emissions from the same vents [Smithsonian Institution 2003]. As already indicated, even with the absence of relevant volcanic activity, the high probabilities that were estimated up to the middle of August 2003 are exclusively linked to the inertia time, as well as to the threshold of $\mathrm{CO}_{2}$, both of which remained fixed after the last eliciting session.

\subsection{The 2004-2005 forecast}

Again, as in the previous period of 2001-2003, the probability estimates for nodes 1 and 2 show similar trends also for the 2004-2005 forecast (constant 100\%, and 87.9\%$96.6 \%$, respectively; Figure 10). Also in this case, a constant tilt anomaly is observed for node 1 .

Apart from a brief period (early March - early May 2004, at $>45.0 \%$ ), the probability of eruption (node 3 ) showed a constant level at around $30.0 \%$, thus indicating a long noanomaly trend in the monitoring dataset. In this period, anomalies were observed in the gravity measurements, which were often accompanied by $\mathrm{CO}_{2}$ emissions. No relevant volcanic activity was reported up to September 7, 2004 [Smithsonian Institution 2004], which was when a new effusive flank eruption occurred from a fracture field that opened on the slope of the South-East Crater and propagating roughly East-South-East [Burton et al. 2005]. Unlike the two previous eruptions, the onset of this flank eruptive event was characterized by the absence of precursor activity, as revealed by the probability estimates that were around the background level, as lower than $30.0 \%$. After about six months of lowintensity lava outflow, the emission stopped on March 8, 2005. Only in early January 2005 and up to early March 2005 were the probabilities $>50.0 \%$ (a maximum probability estimate of $78.8 \%$ ), which reflects the strong anomalies in both the $\mathrm{CO}_{2}$ and $\mathrm{SO}_{2}$ monitoring parameters. After a decreasing trend estimated up to mid-March 2005, a new increasing trend is observed up to the end of April 2005. Again, there was a relevant anomaly in the $\mathrm{CO}_{2}$ parameter, with values close to $50 \mathrm{~g} \mathrm{~m}^{-2}$ day $^{-1}$. No relevant eruptive activity was observed after the end of the September 2004 to the March 2005 flank event.

Due to the absence of precursor activity, no probabilities are estimated for the following node 4 and 5 .

\section{Discussion and conclusions}

A previous application at Mt. Etna of the recently developed technique for eruption forecasting (the BET_EF code) [Marzocchi et al. 2004, 2008] showed that the good performance of this method provides good and quantitative averages relative to the opinions of the experts in terms of what can happen before an eruptive event [Brancato et al., in press].

The present study illustrates the set-up and application of the BET_EF code, with particular focus on the retrospective analysis spanning the period from 2001 to 2005.

Following the first test case [Brancato et al., in press], the monitoring settings were upgraded to fix some coarser thresholds in the parameters that were initially considered with a Boolean approach. Thus, after further elicitation sessions, a thorough revision was allowed, considering all of the monitoring parameters for node 3 under a fuzzy perspective (Figure 2, Table 1).

In addition, the a-priori models were primarily set by taking into account the eruptive flank history of Mount Etna that could be back traced with good guesses over the last 400 years (Figure 3b and 4, Table 3) [Project V3-Lava 2010].

Concerning the probability estimations, the first strong evidence is based on the values of the unrest (node 1). For the whole period analyzed (January 2001 - April 2005), the $100 \%$ estimate highlights that Mount Etna is always under unrest (Figures 5, 7, 9 and 10), which is mostly due to a constant tilt anomaly, and which is often accompanied by persistent volcanic tremor, soil $\mathrm{SO}_{2}$ and $\mathrm{CO}_{2}$ gas emissions, and magma movement activities. For node 2 (magma/no magma) the relative probabilities are mostly $>90.0 \%$, which suggests that magma is deeply involved over this January 2001 to April 2005 unrest phase (Figures 5, 7, 9 and 10).

After the upgrading of the monitoring settings, the relative trends of the probability estimates for node 3 (eruption/no eruption) were able to be tuned more appropriately to the real eruptive occurrences. When no monitoring anomalies are observed, an average of around $30.0 \%$ is estimated (Figures 5, 7, 9 and 10). This confirms, in part, that the monitoring data control the role of the application, when compared with the probability when no unrest is detected (see Figure 3a).

An anomaly in the dataset resulted in the estimation of probability values $>50.0 \%$ (Figures 5 and 7 ). This reflects the capacity of the code to react to some significant variations, which can maybe be interpreted as mid-term precursory activity. Finally, a few days before the onset of a flank eruptive event, different anomalies concurred to give probability estimates $>90.0 \%$ (Figures 5 and 7). This short-term forecasting matches well with the 1-week time window used. When an anomaly persisted because of the relative inertia time window, a lower value was computed that leveled off around $80.0 \%$ (Figure 9).

The grid area adopted (484 square cells; $1 \mathrm{~km}^{2}$ each) in generating the maps for relative probabilities of vent opening (node 4) allowed better insight into the definition of the actual eruptive scenario (Figures 6 and 8).

On the contrary, the relative probability estimates for node 5 (size/style of an eruptive event), do not show any significant variations with time (Table 5).

Despite the good performance of the code, some final 
remarks are appropriate. Of the flank eruptions analyzed here, only the September 2004-March 2005 was no predicted, because no monitoring anomalies occurred (Figure 10). The code is not a 'magic box' that can predict significant volcanic activity, although it can react (in near real-time) to any external variations (i.e. an anomalous monitoring parameter). In any case, an anomalous parameter is not suitable as the definition of the heralding of eruptive activity, as shown with the 'false alarm' on April 20, 2001, when a sudden anomalous increase in the number of shallow earthquakes occurred (Figure 5).

However, an almost constant value of probability of unrest of $100 \%$ is reasonable for an active volcano such as Mount Etna.

Although the whole monitoring setting was revised by the fixing of the relative thresholds and inertia time window according to the recent evolution of the relative time series (Table 1), the role of gas emissions in the estimation of the probability of an eruption (node 3) appears to be extreme. In particular, although barely applied in our investigation, the $\mathrm{CO}_{2}$ parameter elicited did yield some results, the interpretation of which, in terms of precursors, needs great care (Figures 5, 7, 9 and 10). The involvement of the $\mathrm{CO}_{2}$ parameter elicited in the probability estimates starts a few months before impending flank activity, as shown for July to August 2001, October 2002 to January 2003, and September 2004 to March 2005. The anomalies recorded, which lasted for long periods (from weeks to months), appear to reflect the internal dynamics of the volcano, which are not often accompanied by other anomalies, even if this occurs during ongoing volcanic activity (e.g. strombolian eruptions at the summit craters; Figure 5).

On the contrary, during the period of January to midMarch 2005 (Figure 10b), the high estimated probabilities (slightly lower than $80.0 \%$ ) are due exclusively to the geochemical (gas) anomalies. These results are almost linked to anomalies in the $\mathrm{CO}_{2}$ monitoring parameter, and they might suggest a sequence of 'false alarms', with anomalous long-lived times revealed, rather than short-lived spikes. This might be due to the incorrect elicitation of the $\mathrm{CO}_{2}$ parameter in terms of trends, and/or relative thresholds, and/or the related inertia time window.

In any case, the above observations highlight the role of the code in varying probabilities when new data are incoming, also during an ongoing eruption.

During the inter-eruptive period of early February 2003 to September 2004, the high probability of eruption that was estimated from early February to mid-August 2003 (from $68.6 \%$ to $79.2 \%$ ) is due to the slowness of some of the parameters in their resetting towards the no-anomaly values, in agreement with the elicited inertia time window.

The most relevant observation concerns the final node 5 . As set here, it represents only a coarse depiction of the eruptive history of the volcano, as it is improbable at the same time that it can discriminate between the most significant eruptive sizes. Therefore, great care is needed for the clear classification of the features of an eruption, in terms of both the size and type. The suggestion for a reliable model (e.g. a power-law distribution) of the eruptive activity at Mount Etna can be taken into account to better combine the size and the type of eruption. Furthermore, although to date no monitoring parameter provides insights into the size and style of an impending eruption [e.g., Sandri et al. 2004], these might be suggested for a well monitored and very active volcano such as Mount Etna. Therefore, the monitoring elicitation should indicate those parameters that can provide the physical modeling of the volcanic edifice (e.g. three component broadband seismometers, continuous global positioning system and gravimetric measurements, infrasound sensors, thermal cameras, etc.).

The monitoring dataset elicited might prove useful for the Civil Protection, to provide more timely and accurate warnings for the public. The communication of such warnings has become more efficient as well, with the introduction of an alert notification system, similar to that adopted by the United States Geological Survey (USGS; http:/ / volcanoes.usgs.gov/activity / alertsystem). Therefore, on the basis of our results, a preliminary alert system for eruption occurrence (node 3) at Mount Etna volcano can be tentatively proposed. Green (normal), yellow (advisory), orange (watch) and red (warning) levels can be defined easily by the Authority on the basis of different probability values. Such a proposed system should allow both critical decisions and dissemination of information to be made easier.

Acknowledgements. The authors wish to thank Don Dingwell, Jörg Keller, Warner Marzocchi and Chris Newhall for their fruitful discussions and suggestions. Alexander McBirney and Nick Varley are sincerely acknowledged for the constructive criticism and a careful review of an early version of the manuscript, and Stephen D. Conway is thanked for his careful review of the English text. This study benefited from funding provided by the Italian Presidenza del Consiglio dei Ministri, Dipartimento della Protezione Civile (DPC, 2007-2009 V3 Lava project). Scientific papers funded by DPC do not represent its official opinion and policies.

\section{References}

Aiuppa, A., P. Allard, W. D’Alessandro, S. Giammanco, F. Parello and M. Valenza (2004). Magmatic gas leakage at Mount Etna (Sicily, Italy): relationships with the volcano-tectonic structures, the hydrological pattern and the eruptive activity, in Mt. Etna: Volcano Laboratory (A. Bonaccorso, S. Calvari, M. Coltelli, C. Del Negro, S. Falsaperla Editors). American Geophysical Union, Washington, DC, Geophysical Monograph Series 143, 129-145; doi: 10.1029/143GM09.

Aloisi, M., A. Bonaccorso and S. Gambino (2006). Imaging composite dike propagation (Etna, 2002 case), J. Geophys. Res, 111, B06404; doi: 10.1029/2005JB003908. 
Alparone, S., D. Andronico, L. Lodato and T. Sgroi (2003). Relationship between tremor and volcanic activity during the Southeast Crater eruption on Mount Etna in early 2000, J. Geophys. Res., 108 (B5), 2241; doi: 10.1029/ 2002JB001866.

Andronico, D., S. Branca, S. Calvari, M. Burton, T. Caltabiano, R.A. Corsaro, P. Del Carlo, G. Garfi, L. Lodato, L. Miraglia, F. Murè, M. Neri, E. Pecora, M. Pompilio, G. Salerno and L. Spampinato (2005). A multi-disciplinary study of the 2002-03 Etna eruption: insights into a complex plumbing system, B. Volcanol., 67, 314-330.

Barberi, G., O. Cocina, V. Maiolino, C. Musumeci and E. Privitera (2004). Insight into Mt. Etna (Italy) kinematics during the 2002-2003 eruption as inferred from seismic stress and strain tensors, Geophys. Res. Lett., 31, L21614; doi: 10.1029/2004GL020918.

Behncke, B., M. Neri, E. Pecora and V. Zanon (2006). The exceptional activity and growth of the Southeast Crater, Mount Etna (Italy), between 1996 and 2001, B. Volcanol., 69, 149-173.

Bonaccorso, A., M. Aloisi and M. Mattia (2002). Dike emplacement forerunning the Etna July 2001 eruption modelled through continuous tilt and GPS data, Geophys. Res. Lett., 29, 13; doi: 10.1029/2001GL014397.

Bonaccorso, A., S. D'Amico, M. Mattia and D. Patanè (2004). Intrusive mechanism at Mt. Etna forerunning the July-August 2001 eruption, Pure Appl. Geophys., 161 (7), 1469-1487; doi: 10.1007/s00024-004-2515-4.

Bonforte, A., F. Guglielmino, M. Palano and G. Puglisi (2004). A syn-eruptive ground deformation episode measured by GPS, during the 2001 eruption on the upper southern flank of Mt. Etna, B. Volcanol., 66, 336-341.

Branca, S. and P. Del Carlo (2005). Types of eruptions at Etna volcano AD 1670-2003: implications for short-term eruptive behaviour, B. Volcanol., 67, 737-742.

Brancato, A., S. Gresta, L. Sandri, J. Selva, W. Marzocchi, S. Alparone, D. Andronico, A. Bonforte, T. Caltabiano, O. Cocina, R.A. Corsaro, R. Cristofolini, G. Di Grazia, G. Distefano, C. Ferlito, S. Gambino, S. Giammanco, F. Greco, R. Napoli, G. Tusa and M. Viccaro. Quantifying probabilities of eruption at a well-monitored active volcano: an application at Mount Etna (Sicily, Italy), B. Geofis. Teor. Appl., (in press).

Bruno, N., T. Caltabiano, S. Giammanco and R. Romano (2001). Degassing of $\mathrm{SO}_{2}$ and $\mathrm{CO}_{2}$ at Mount Etna (Sicily) as an indicator of pre-eruptive ascent and shallow emplacement of magma, J. Volcanol. Geoth. Res., 110, 137-153.

Burton, M.R., M. Neri, D. Andronico, S. Branca, T. Caltabiano, S. Calvari, R. A. Corsaro, P. Del Carlo, G. Lanzafame, L. Lodato, L. Miraglia, G. Salerno and L. Spampinato (2005). Etna 2004-2005: An archetype for geodynamically-controlled effusive eruptions, Geophys.
Res. Lett., 32, L09303; doi: 10.1029/2005GL022527.

Caltabiano, T., R. Romano and G. Budetta (1994). $\mathrm{SO}_{2}$ flux measurements at Mount Etna (Sicily), J. Geophys. Res., 99, 12809-12819.

Carbone, D., G. Budetta and F. Greco (2003). Bulk processes prior to the 2001 Mount Etna eruption, highlighted through microgravity studies, J. Geophys. Res., 108 (B12), 2556; doi: 10.1029/2003JB002542.

Carbone, D. and F. Greco (2007). Review of microgravity observations at Mt. Etna: a powerful tool to monitor and study active volcanoes, Pure Appl. Geophys., 164, 769-790.

Corsaro, R.A., L. Civetta, V. Di Rienzo and L. Miraglia (2009). Petrology of lavas from the 2004-2005 flank eruption of Mt. Etna, Italy: inferences on the dynamics of magma in the shallow plumbing system, B. Volcanol., 71, 781-793.

Cristofolini, R., S. Gresta, S. Imposa and G. Patanè (1988). Feeding mechanism of eruptive activity at Mt. Etna based on seismological and petrological data, In: Y. King and R. Scarpa (eds.), Modelling of Volcanic Processes, Vieweg-Verlag, Wiesbaden, 73-93.

Del Negro, C., G. Currenti, R. Napoli and A. Vicari (2004). Volcanomagnetic changes accompanying the onset of the 2002-2003 eruption of Mt. Etna (Italy), Earth Planet. Sci. Lett., 229, 1-14.

Falsaperla, S., S. Alparone, S. D’Amico, G. Di Grazia, F. Ferrari, H. Langer, T. Sgroi and S. Spampinato (2005). Volcanic tremor at Mt. Etna, Italy, preceding and accompanying the eruption of July-August 2001, Pure Appl. Geophys., 162, 2111-2132.

Marzocchi, W., L. Sandri, P. Gasparini, C. Newhall and E. Boschi (2004). Quantifying probabilities of volcanic events: The example of volcanic hazard at Mount Vesuvius, J. Geophys. Res., 109, B11201; doi: 10.1029/ 2004JB00315U.

Marzocchi, W., L. Sandri and J. Selva (2008). BET_EF: a probabilistic tool for long- and short-term eruption forecasting, B. Volcanol., 70, 623-632.

Monaco, C., S. Catalano, O. Cocina, G. De Guidi, C. Ferlito, S. Gresta, C. Musumeci and L. Tortorici (2005). Tectonic control on the eruptive dynamics at Mt. Etna volcano (Sicily) during the 2001 and 2002-2003 eruptions, J. Volcanol. Geoth. Res., 144, 211-233.

Neri, M., V. Acocella and B. Behncke (2004). The role of the Pernicana Fault System in the spreading of Mt. Etna (Italy) during the 2002-2003 eruption, B. Volcanol., 66, 417-430.

Newhall, C. G. and R. P. Hoblitt (2002). Constructing event trees for volcanic crises, B. Volcanol., 64, 3-20.

Patanè, D., E. Privitera, S. Gresta, A. Akinci, S. Alparone, G. Barberi, L. Chiaraluce, O. Cocina, S. D’Amico, P. De Gori, G. Di Grazia, S. Falsaperla, F. Ferrari, S. Gambino, 
E. Giampiccolo, H. Langer, V. Maiolino, M. Moretti, A. Mostaccio, C. Musumeci, D. Piccinini, D. Reitano, L. Scarfi, S. Spampinato, A. Ursino and L. Zuccarello (2003). Seismological constraints for the dike emplacement of July-August 2001 lateral eruption at Mt. Etna volcano, Italy, Annals of Geophysics, 46 (4), 599-608.

Project V3-LAVA (2010). Realization of the lava flow invasion hazard map at Mt. Etna and method for its dynamic update, DPC-INGV 2007-2009 agreement, Final Scientific Report, 196 pp.

Sandri, L., W. Marzocchi and L. Zaccarelli (2004). A new perspective in identifying the precursory patterns of volcanic eruptions, B. Volcanol., 66, 263-275.

Smithsonian Institution (2000-2004). Etna activity reports, Bull. Global Volcanism Network.

${ }^{\star}$ Corresponding author: Alfonso Brancato,

Università degli Studi di Catania, Dipartimento di Scienze Geologiche, Catania, Italy; e-mail: abranca@unict.it.

(C) 2011 by the Istituto Nazionale di Geofisica e Vulcanologia. All rights reserved. 